\title{
Thrombospondin-4 mediates hyperglycemia- and TGF-beta-induced inflammation in breast cancer
}

\author{
Santoshi Muppala ${ }^{1}$, Roy Xiao ${ }^{1,2}$, Jasmine Gajeton ${ }^{1,2}$, Irene Krukovets ${ }^{1}$, Dmitriy \\ Verbovetskiy $^{1}$, and Olga Stenina-Adognravi ${ }^{1}$ \\ ${ }^{1}$ Department of Cardiovascular and Metabolic Sciences, \\ ${ }^{2}$ Cleveland Clinic Lerner College of Medicine/CWRU, \\ Cleveland Clinic, Cleveland, Ohio
}

${ }^{*}$ Correspondence:

Olga Stenina-Adognravi

Department of Molecular Cardiology, Cleveland Clinic

9500 Euclid Ave NB50-78, Cleveland, OH 44195

(216) 444-9057

stenino@ccf.org

Word count: 3,902

Figures: 6

Tables: 0

Supplementary material: 1 figure and 6 tables

Novelty and Impact: Thrombospondin-4 (TSP-4) is a secreted extracellular protein that belongs to the family of matricellular proteins. TSP-4 is one of the top $1 \%$ of proteins upregulated in several cancers, including breast cancer. Inflammation and infiltration of macrophages drive cancer progression and metastasis and are clinically important markers of cancer aggressiveness and critical consideration in the process of selection of the appropriate therapeutic approaches. We report that TSP-4 promotes breast cancer inflammation and infiltration of macrophages and mediates the effects of hyperglycemia and TGF-beta on cancer growth and inflammation. Our work describes a role for TSP-4 in cancer inflammation and identifies the pathways, in which increased levels of TSP-4 mediate cancer growth. 


\section{Abbreviations}

\begin{tabular}{|c|c|}
\hline ActB & beta-actin gene \\
\hline ANOVA & Analysis of variance \\
\hline Arg1 & Arginase 1 \\
\hline BMDM & bone-marrow-derived macrophages \\
\hline $\mathrm{Ccl} 2$ & chemokine ligand 2, also known as monocyte chemoattractant protein 1 \\
\hline CD38 & Cluster of Differentiation 38 \\
\hline CD68 & Cluster of Differentiation 68 \\
\hline cDNA & complementary DNA (deoxyribonucleic acid) \\
\hline Coll & collagen I \\
\hline Col IV & collagen IV \\
\hline DMEM & Dulbecco's Modified Eagle Medium \\
\hline EC & endothelial cell \\
\hline ECM & extracellular matrix \\
\hline Egr2 & early growth response protein 2 \\
\hline Gapdh & Glyceraldehyde 3-phosphate dehydrogenase gene \\
\hline $\mathrm{HbAc1}$ & glycated hemoglobin \\
\hline II-6 & interleukin-6 \\
\hline iNOS & Inducible Nitric Oxide Synthase \\
\hline IP & intraperitoneal \\
\hline M-CSF & Macrophage Colony Stimulating Factor \\
\hline MCP-1 & macrophage chemoattractant protein \\
\hline mRNA & Messenger RNA \\
\hline $\mathrm{NIH}$ & National Institutes of Health \\
\hline Nos2 & Nitric Oxide Synthase 2 (Inducible Nitric Oxide Synthase) gene \\
\hline P387-TSP4-KI & knock-in mice with $A$ to $P$ mutation in position 387 \\
\hline Rn18s & $18 \mathrm{~S}$ ribosomal RNA \\
\hline RT-PCR & Reverse transcription polymerase chain reaction \\
\hline S.E.M. & standard error of the mean \\
\hline STZ & streptozotocin \\
\hline TAM & tumor-associated macrophages \\
\hline TGF-beta & Transforming Growth Factor-beta \\
\hline Thbs4 & TSP-4 gene \\
\hline TNF-alpha & Tumor necrosis factor alpha \\
\hline TSP-4 & thrombospondin-4 \\
\hline vWF & von Willebrand factor \\
\hline WT & wild type \\
\hline
\end{tabular}




\section{Abstract}

Inflammation drives the growth of tumors and is an important predictor of cancer aggressiveness. CD68, a marker of tumor-associated macrophages (TAM), is routinely used as a marker to aid in prognosis and treatment choices for breast cancer.

We report that thrombospondin-4 (TSP-4) mediates breast cancer inflammation and growth in mouse models in response to hyperglycemia and TGF-beta by increasing TAM infiltration and production of inflammatory signals in tumors. Analysis of breast cancers and non-cancerous tissue specimens from hyperglycemic patients revealed that levels of TSP-4 and of macrophage marker CD68 are upregulated in diabetic tissues. TSP-4 was co-localized with macrophages in cancer tissues. Bone-marrowderived macrophages (BMDM) responded to high glucose and TGF-beta by upregulating TSP-4 production and expression, as well as the expression of inflammatory markers.

We report a novel function for TSP-4 in breast cancer: regulation of TAM infiltration and inflammation. The results of our study provide new insights into regulation of cancer growth by hyperglycemia and TGF-beta and suggest TSP-4 as a potential therapeutic target. 
bioRxiv preprint doi: https://doi.org/10.1101/2020.01.03.894436; this version posted December 14, 2020. The copyright holder for this preprint (which was not certified by peer review) is the author/funder. All rights reserved. No reuse allowed without permission.

Keywords: thrombospondin-4, macrophage, inflammation, breast cancer, matricellular proteins 


\section{Introduction}

Cancer growth depends on the interplay between the cancer cells and the tumor microenvironment. Tumor inflammation is modulated by the infiltration of immune cells and is closely associated with the tumor aggressiveness and metastasis (1). Activated cancer and vascular cells produce chemoattractants and pro-inflammatory signals to recruit inflammatory cells from blood. The accumulation of inflammatory cells in a tumor is an important prognostic index that has been successfully used to evaluate the aggressiveness of cancer in conjunction with other indexes describing the proliferation rate of cancer cells and their migratory potential. For example, one of the 12 markers evaluated in Oncotype DX (a test used to predict the aggressiveness of breast cancer and to make therapeutic decisions) is CD68, a marker of macrophages (2).

The composition of the extracellular matrix (ECM) regulates recruitment of immune cells and their interactions with other cell types in a tumor. In recent years, the role of ECM, and of matricellular proteins specifically, in regulation of inflammatory cell functions attracted more attention (3-5). Thrombospondins (TSP), the matricellular proteins that are not structural but regulate cell-ECM and cell-cell interactions, belong to a family that consists of five distinct members with distinct properties and roles in inflammation (6). While the functions of TSP-1 in regulation of inflammation have been somewhat examined, the roles for other TSPs are unknown. TSP4 is especially interesting as a potential regulator of inflammation, due to its highly upregulated levels in several conditions linked to inflammation, including coronary artery disease, heart failure, and cancers (3,7-12). Indeed, we found that TSP-4 regulates cancer growth $(13,14)$ and 
promotes pro-inflammatory polarization of macrophages (5), in addition to regulation of the blood and vascular cells adhesion, migration, and activation $(3,5)$. However, the role of TSP-4 in regulation of cancer inflammation and infiltration of tumors with macrophages remained unknown. Here, we report that TSP-4 regulates cancer inflammation by increasing tumor infiltration with tumor-associated macrophages (TAM) and the levels of pro-inflammatory markers.

A rapidly-growing body of evidence connects hyperglycemia, insulin resistance, and glucose intolerance with cancer risk and progression (15-24). Diabetes, pre-diabetes, and metabolic syndrome are associated with chronic inflammation $(25,26)$, and high glucose promotes pro-inflammatory polarization of macrophages $(27,28)$ in vitro. To understand the role of TSP-4 as a mediator of hyperglycemia-induced cancer inflammation, we examined TSP-4 levels in breast cancer xenografts in mouse models of hyperglycemia and in the breast cancer tissues of hyperglycemic patients, as well as the effects of high glucose on cultured macrophages.

TGF-beta is a major regulator of tissue remodeling and inflammation and the main regulator of ECM production $(29,30)$, a function critical in many pathological conditions, including cancer. As a cytokine with well-studied receptors and intracellular signaling, TGF-beta and the pathways it activates are attractive therapeutic targets. However, TGF-beta has cell- and process-specific effects that are sometimes distinct and even opposite, depending on a stage and localization of a process (so-called "TGF-beta paradox) (31). In cancer, TGF-beta suppresses the growth of tumor at the early stages by inducing apoptosis and cell cycle arrest in cancer cells and by supporting cell 
differentiation. However, at the later stages associated with increased inflammation and angiogenesis, TGF- $\beta$ promotes tumor growth and metastasis by modulating the tumor microenvironment. We found that TGF-beta is a potent inducer of TSP-4 production in endothelial cells and macrophages $(5,14)$. Thus, one of the goals of the current report was to demonstrate the role of TSP-4 as a process-specific mediator of TGF-beta effects on cancer inflammation.

Our report demonstrates the effect of TSP-4 on cancer inflammation and the role of TSP-4 as a mediator of the effects of hyperglycemia and TGF-beta, two recognized drivers of cancer inflammation, growth, and metastasis with incompletely understood mechanisms of action. 


\section{Materials and Methods}

\subsection{Patient's breast cancer and adjacent normal tissue specimens were obtained} from the Cleveland Clinic Tissue Bank. The work was approved by the Cleveland Clinic Institutional Review Board. All patients were female. Patients with $\mathrm{HbAc} 1<6$ were considered normoglycemic; patients with $\mathrm{HbAc} 1>7$ or documented diabetes diagnosis were considered hyperglycemic. The patient information is summarized in Supplemental Tables 1 and 2. H\&E stained sections of tumors from normoglycemic and hyperglycemic patients are shown in Suppl. Fig. 1 (top four panels).

2.2. Animals. Mice were of the C57BL/6 background. Both genders were used. Thbs $4^{-/-}$and P387-TSP4-KI mice were described previously (5). Animal procedures were approved by the IACUC and in agreement with the NIH Guide for Animal Use.

2.3. Induction of hyperglycemia in mice. Hyperglycemia was induced by streptozotocin (STZ) injections $(32,33)$. Mice with levels $\geq 250 \mathrm{mg} / \mathrm{dl}$ were included in the experiments.

2.4. EMT6 mouse breast cancer xenografts. Fifteen- to sixteen-week-old mice were anesthetized by IP injection of Ketamine $(80 \mathrm{mg} / \mathrm{kg}) /$ Xylazine $(15 \mathrm{mg} / \mathrm{kg})$ mixture. Mice were injected in the mammary fat pad with $1.5 \times 10^{6}$ EMT6 cells (RRID:CVCL_1923) (ATCC) in $100 \mu \mathrm{l}$ of saline. All experiments were performed with mycoplasma-free cells. TGF- $\beta 1$ (500ng/kg) injections were given IP daily for 14 days. The injected amount of TGF- $\beta 1$ was based on reported studies in mice $(34,35)$ and our previous work $(14)$. Tumors were harvested at the end of the experiment. H\&E stained representative 
sections of EMT6 xenografts from normoglycemic and hyperglycemic mice are shown in Suppl. Fig.1, four bottom panels.

2.5. Bone Marrow Derived Macrophages (BMDM). BMDM were isolated from tibia of

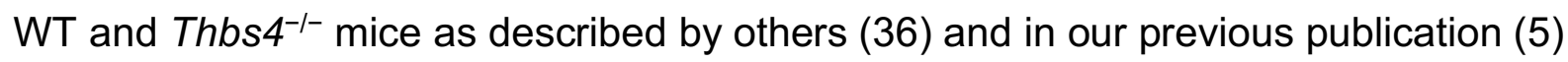
and cultured in M-CSF (14-8983-62, ThermoFisher)/DMEM/F12 for 5 days. 95-98\% of cultured cells were identified as macrophages by immunohistochemistry and FACS analysis.

BMDM were treated either with D-Glucose $(30 \mathrm{mM})$ or TGF-beta $(10 \mathrm{ng} / \mathrm{ml})$ for $6 \mathrm{~h}$ and $24 \mathrm{~h}$ respectively, along with proper controls. The concentrations of D-Glucose and TGFbeta were selected based on previous studies in BMDM and other cultured cells $(5,14,32,33,37-42) .30 \mathrm{mM}$ D-Glucose was producing the maximal effects while still reflecting a naturally occurring blood level of glucose in vivo.

\subsection{Quantitative real-time RT-PCR analysis. Total RNA was extracted using TRIzol} Reagent (\#15596026, ThermoFisher) followed by cDNA synthesis using SuperScript ${ }^{\mathrm{TM}}$ First-Strand Synthesis System (\#11904018, ThermoFisher). Taqman fast Master mix (\#4444557, ThermoFisher). The TaqMan® probes for specific gene products, with ActB, Gapdh, and Rn18s as housekeeping gene controls.

\subsection{Immunohistochemistry, immunofluorescence, confocal imaging and} quantification of macrophage markers. $10 \mu \mathrm{m}$ sections of mouse tumors were stained with primary rat anti-mouse CD68 antibody (MCA1957B, Bio-Rad), and goat anti-human TSP-4 (AF2390, R\&D Systems). Sections of human tumors were stained 
with mouse anti-human CD68 (Dako) and goat anti-human TSP-4 (AF2390, R\&D

Systems) using Vecta Stain ABC Kit (PK-6104, PK-6102, PK-6105 Vector).

Visualization after staining with the antibodies was performed using a high-resolution slide scanner (Leica SCN400FL, Leica microsystems, GmbH, Wetzlar, Germany) at 20

× magnification. For immunofluorescence, Collagen I (Ab6308, Abcam) and Collagen IV (Ab6586, Abcam), rat anti-mouse CD68 (MCA1957B, Bio-Rad), goat anti-human TSP-4 (AF2390, R\&D Systems), monoclonal mouse anti-human alpha smooth muscle actin (M0851, Dako), monoclonal mouse anti-human CD68 (M0814, Dako), rabbit anti-human VWF antibody (A0082, Dako), were used with corresponding secondary antibodies. Images were taken at a high-resolution confocal microscope (Leica DM 2500).

High-resolution images of the whole section were generated and quantified to determine the percentage of the stained area using ImagePro 6.1. Quantification was performed by investigator blinded to the assignment of animals between groups. The number of pixels in the whole section of tissue (excluding area without tissue and large gaps in tissue specimen) was defined as total area. The stained area (colored) was selected and quantified in pixels, and the percent of stained are was calculated.

Representative H\&E images of tumors from mice and patients are shown in Suppl. Fig. 1.

2.8. Statistical analysis. Analyses of the data were performed using Sigma Plot Software (Systat Software, San Jose, CA, USA): Student's t-test and ANOVA were used to determine the significance of parametric data, and Wilcoxon rank sum test was 
bioRxiv preprint doi: https://doi.org/10.1101/2020.01.03.894436; this version posted December 14, 2020. The copyright holder for this preprint (which was not certified by peer review) is the author/funder. All rights reserved. No reuse allowed without permission.

used for nonparametric data. The significance level was set at $p=0.05$. The data are presented as mean \pm S.E.M. 


\section{Results}

\subsection{TSP-4 deletion reduces inflammation in mouse breast cancer}

To understand the role of TSP-4 in cancer inflammation, EMT6 cells transduced with TSP-4 shRNA (13) were injected into WT or Thbs4 ${ }^{-/}$mice (Fig.1A). Although we could not detect TSP-4 production by cultured EMT6, we found that EMT6 cells do produce trace amounts of TSP-4 in vivo, and the best inhibition of BC tumor growth was observed with BC cells with suppressed TSP-4 production (13).

The expression of a macrophage marker $\mathrm{Cd} 68$, a marker of pro-inflammatory macrophages Cd38, a marker of tissue resolving macrophages Egr2, and Cc/2 (MCP-1) was quantified by Real-Time RT-PCR (Fig.1A). Cd68 and pro-inflammatory markers Cd38 and Cc/2 expression was decreased in Thbs4 ${ }^{-/}$mice, indicating that TSP-4 promotes macrophage infiltration of tumors and inflammation. Cd68 expression was decreased from $1.36 \pm 0.19$ to $0.75 \pm 0.11, p=0.01 ; C c / 2$ (MCP-1) expression was decreased from $1.37 \pm 0.22$ to $0.26 \pm 0.03, p=0.0003$, indicating a lower level of inflammation in the absence of TSP-4.

\subsection{Effect of TSP-4 deletion on expression of inflammatory markers in cultured bone-marrow-derived macrophages (BMDM)}

Expression of markers of macrophage polarization and inflammatory markers was measured in BMDM from WT and Thbs4-- mice (Fig.1B). Deletion of Thbs4 resulted in significantly decreased expression of most markers, with the exception of one of the 
markers of pro-inflammatory macrophages Nos2 and one of the markers of tissue repair macrophages Arg1: both were significantly upregulated in BMDM from TSP-4 KO mice.

\subsection{Increased TSP-4 expression in breast cancer tumors of hyperglycemic animals}

We reported that hyperglycemia accelerates the growth and angiogenesis in mouse models [40]. To understand the role of TSP-4 in regulations of hyperglycemia-induced inflammation that also drives the cancer growth, two mouse models of hyperglycemia, STZ-treated WT C57BL/6 mice (model of type 1 diabetes) and Lepr ${ }^{d b / d b}$ (genetic model of type 2 diabetes) were used, and TSP-4 expression and protein levels were examined in EMT6 mouse breast cancer xenografts (Fig.2 A and B). RNA was purified from the tumors, and levels of mRNA of thrombospondin-4 (Thbs4) were measured by RealTime RT-PCR (Fig.2A and B, top left panels, and Supplemental Table 3). TSP-4 expression was significantly upregulated in tumors of both mouse models.

EMT6 tumors from hyperglycemic mice were stained with anti-TSP-4 antibody to examine localization of TSP-4 in tumors and the levels of TSP-4 proteins. TSP-4 protein levels were also significantly upregulated in response to hyperglycemia (Fig.2C and 2D). In hyperglycemic STZ-treated mice, immunofluorescence detected increased levels of TSP-4 (Fig.2C, red), and co-staining with anti-CD68 antibody against macrophage marker (green) revealed that TSP-4 was co-localized with CD68, a marker of macrophages. 


\subsection{Increased TSP-4 expression and protein levels in breast cancer tumors of hyperglycemic patients}

Immunohistochemistry was used to detect and quantify the levels of TSP-4 protein in patients' breast cancer tumors and non-cancerous adjacent breast tissue (Fig.3). TSP-4 protein levels were higher in breast cancer tissue as compared to adjacent noncancerous tissue and increased in both the cancerous and non-cancerous tissues of diabetic patients (Fig.3A, right panel) $(7.01 \pm 0.38 \%$ of total area of a section in tumor vs $3.32 \pm 0.41 \%$ in non-cancerous in hyperglycemic patient, $p=0.02$ and $4.73 \pm 0.21 \%$ in tumor vs $1.03 \pm 0.20 \%$ in non-cancerous in normoglycemic patients, $p=0.03$ ).

When breast cancer tissue specimens from hyperglycemic ( $\mathrm{HbAc1>7)}$ and normoglycemic $(\mathrm{HbAc} 1<6)$ patients were examined, most TSP-4 was associated with macrophages (Fig.3B), although co-staining with a marker of endothelial cells (EC) vWF (purple) was also detected.

\subsection{Increased TAM infiltration in breast cancer tumors of hyperglycemic animals and patients}

mRNA of a macrophage marker CD68 was upregulated in EMT6 tumors of STZ-treated and Lepr $r^{d b / d b}$ mice (Fig.2A and B) suggesting increased number of macrophages in cancer xenografts in hyperglycemic mice.

Increased number of macrophages in tumors of hyperglycemic animals was detected by immunofluorescence and immunohistochemistry with anti-CD68 antibody (Fig.2C and 2D): the area stained with anti-CD68 increased from $1.70 \pm 0.19 \%$ of total area of a 
section in control normoglycemic mice to $3.51 \pm 0.62 \%$ in STZ-treated hyperglycemic mice, $p=0.005$ (Fig.2D, top left panel). Immunohistochemistry with MOMA-2, another antibody recognizing mouse macrophages, supported the data obtained with anti-CD68 antibody: area stained with MOMA-2 antibody significantly increased in tumors from hyperglycemic mice (Fig.2D, top right panel).

CD68 protein levels were higher in breast cancer tissue of patients as compared to adjacent non-cancerous tissue (stained area $3.63 \pm 0.20 \%$ of total section area in tumor vs $2.2 \pm 0.27 \%$ in non-cancerous in hyperglycemic patient, $p=0.04$ and $2.26 \pm 0.10 \%$ in tumor vs $1.01 \pm 0.20 \%$ in non-cancerous in normoglycemic patients, $p=0.01$ ) (Fig.3A, left panels). The levels of CD68 were significantly higher in diabetic tissues, in both the cancerous and the non-cancerous adjacent tissue (Fig.3A, left panels)..

In both the animal and patients' tumors, TSP-4 was associated predominantly with macrophages (Fig. 2C and 3B).

\subsection{Increased inflammation in EMT6 mouse breast cancer of hyperglycemic mice}

The levels of all inflammatory and TAM markers were significantly increased in tumors from STZ-treated mice (Fig.2A - D and Supplemental Table 3), indicating a higher level of inflammation and increased TAM infiltration in tumors of hyperglycemic animals but also suggesting that tissue repair macrophages have been recruited into tumors along with pro-inflammatory macrophages.

All inflammation and macrophage markers were upregulated in hyperglycemic $L e p r^{d b / d b}$ mice (Fig.2B and Supplemental Table 3). 


\subsection{Effect of TSP-4 deletion on the expression of inflammatory markers by BMDM in response to high glucose}

The role of TSP-4 in high-glucose-induced upregulation of inflammatory markers was tested using BMDM isolated from WT mice and from Thbs4-/mice (Fig.4A and Suppl. Table 4). Deletion of TSP-4 prevented the high-glucose-induced increases in mRNA levels of macrophage marker $C d 68$, of markers of pro-inflammatory macrophages $C d 38$ and Nos2, a marker of tissue-repair macrophages Arg1, and increase in Tnf levels without an effect on Egr2, Cc/2, and I/6.

\subsection{Effect of high glucose on TSP-4 protein production in cultured bone-marrow- derived macrophages (BMDM)}

Because most of TSP-4 protein was co-localized with TAM in tumors, we isolated bonemarrow-derived macrophages (BMDM) from WT, Thbs4 $4^{-1}$ (TSP-4 KO mice), and P387TSP-4 KI mice expressing a mutant form of TSP-4 that is more active in all cellular interactions $(4,5,13,14,40,43,44)$. Cultured BMDM were incubated in low $(5 \mathrm{mM}) \mathrm{D}$ glucose or high (30 mM) D-glucose and stained with anti-CD68 and anti-TSP-4 (Fig. 4B and C).

TSP-4 levels were increased in BMDM isolated from WT mice in response to high glucose and were higher in cultured BMDM from P387-TSP-4-KI mice, consistent with our previous observations of higher stability and activity of the mutant protein $(43,44)$. High glucose did not increase the levels of CD68 in P387-TSP-4-KI mice. The deficiency in TSP-4 (Thbs4 ${ }^{-/}$, TSP-4 KO) reduced the level of CD68 (Fig.4B). 


\subsection{TGF-beta increases inflammation in mouse breast cancer}

Previously, we reported that TGF-beta accelerates the growth of EMT6 xenografts and cancer angiogenesis in mice, and that TSP-4 is a mediator of TGF-beta effects on cancer angiogenesis [14]. Because cancer inflammation drives the tumor growth, we examined the effect of TGF-beta1 injections on TSP-4 and inflammation in mouse EMT6 cancer. Mice with EMT6 xenografts were injected intraperitoneally with $500 \mathrm{ng} / \mathrm{kg}$ TGF-beta daily. The expression of TSP-4 gene and inflammation markers was examined by Real-Time RT-PCR (Fig.5A and Supplemental Table 5). Daily TGF-beta1 injections resulted in increased levels of Thbs4, Cd68, II6, Cc/2 (MCP-1), and Tnf. The levels of a marker of pro-inflammatory macrophages $C d 38$ were increased by TGFbeta1 injections, while the level of a marker of tissue-repair macrophages Egr1 was decreased.

\subsection{Increased macrophage infiltration in breast cancer tumors of mice injected with TGF-beta1}

Increased number of macrophages in tumors of animals injected with TGF-beta1 was detected by immunohistochemistry with anti-CD68 antibody (Fig.5B). The area stained with anti-CD68 antibody was decreased in Thbs4 $4^{-/}$mice.

\subsection{Effect of TSP-4 deletion on the expression of inflammatory markers by BMDM in response to TGF-beta1}

Effect of TSP-4 KO was examined in cultured BMDM stimulated with TGF-beta1 (Fig. 6A and Suppl. Table 6). The expression of $C d 68$ and $C d 38$ was only modesty 
upregulated by TGF-beta1 in WT cells, and this modest upregulation was prevented by TSP-4 deletion. Nos2 levels were significantly increased by TGF-beta1 in WT cells, and the increase was completely prevented in BMDM from Thbs4/- mice. Increase in Arg1, II6 and Tnf expression was significant and unaffected by the lack of TSP-4. Egr1 and Ccl2 expression was decreased by TGF-beta1 in cells from mice of both genotypes.

\subsection{TSP-4 does not mediate the effects of TGF-beta on collagen production}

To investigate whether TSP-4 mediates other effects of TGF-beta1 in breast cancer tumors, in addition to regulation of angiogenesis and inflammation, we examined collagen I and IV (Col I and IV) levels in tumors grown in WT and Thbs4 $4^{-/-}$mice (Fig.6B). Both Col I and Col IV levels were increased in Thbs4 $4^{-/}$mice, consistent with our previous observation of suppression of collagen production by TSP-4 (45). TGF-beta1 decreased the level of Col I in a TSP-4-dependent manner: the decrease was completely prevented in Thbs $4^{-/-}$mice. The levels of Col IV were decreased in response to TGF-beta1 injections independently of the presence or the absence of TSP-4, suggesting that TSP-4 does not mediate the effect of TGF-beta on collagen IV production or turnover. 


\section{Discussion}

TSP-4 is one of the top upregulated genes in several cancers, including the breast cancer $(12,46,47)$. Using Thbs4-/ mice, we demonstrated that TSP-4 deletion prevents the growth of cancer and mediates TGF-beta1 effect on cancer angiogenesis (14). Tumor inflammation is an important marker of cancer aggressiveness and is defined by the tumor microenvironment, including the composition of the tumor ECM. We recently reported that TSP-4 promotes the accumulation of macrophages in tissues and regulates their pro-inflammatory polarization, adhesion, and migration $(3,5)$. Taking in the account the dramatically increased levels of TSP-4 in some cancers, its effects on tumor growth, and its role in regulation of macrophage polarization and function, we investigated here whether TSP-4 regulates cancer inflammation.

Two well-known regulators of ECM production, inflammation, and cancer growth hyperglycemia $(15,16,48)$ and TGF-beta $(14,49,50)$ - are known to regulate the remodeling of tissues and of cancer microenvironment. Both have poorly understood effects on cancer growth and ECM. We have examined these two stimuli to define the role of TSP-4 in pro-inflammatory effects of TGF-beta and hyperglycemia and found that in both pathways TSP-4 mediates macrophage infiltration and cancer inflammation and growth.

First, we documented that TSP-4 promotes infiltration of macrophages in EMT6 tumors and inflammation. The deletion of TSP-4 in mice (Thbs4 $\left.4^{-/-}\right)$and EMT6 cancer cells [EMT6 stably transduced with TSP-4 shRNA] resulted in significantly reduced expression of macrophage marker CD68, pro-inflammatory macrophage marker CD38, 
$\mathrm{CCl} 2$ (MCP-1), but not a marker of tissue repair macrophages Egr2, consistent with regulation of macrophage infiltration and upregulation of inflammation by TSP-4 $(3,5)$.

Experiments in cultured BMDM supported pro-inflammatory effect of TSP-4: the expression of $\mathrm{Cc} / 2,1 / 6, \mathrm{Tnf}$, and $\mathrm{Cd} 38$ was reduced in BMDM from TSP-4 KO mice. However, these experiments suggested a more complex effect of TSP-4 on macrophage differentiation, because the levels of the general marker of macrophages Cd68 was also reduced, and another marker of pro-inflammatory macrophages, Nos2, was upregulated in TSP-4 KO cells. The complexity of the effects on differentiation was also clear from the inconsistent effects on both the markers of pro-inflammatory macrophages (Cd38 levels were decreased while Nos2 levels were increased in BMDM from the TSP-4 KO mice) and tissue repair macrophages (Egr2 levels were decreased while Arg1 levels were increased in BMDM from the TSP-4 KO mice). The differential effects on the specific markers suggest that TSP-4 promotes a very specific pathway of polarization of macrophages favoring a subtype that is not the major pro-inflammatory subtype. The complexity of TSP-4 role in macrophage polarization and differential roles of TSP-4 in pathways initiated by various inflammatory stimuli was discussed in our previous publication (5).

Several markers of inflammation were examined in breast cancer tissues of hyperglycemic mice and patients: inflammatory cytokines IL-6, CCL2 (MCP-1) and TNFalpha, as well as a macrophage marker CD68, markers of pro-inflammatory macrophages CD38 and iNOS, and markers of tissue repair anti-inflammatory macrophages EGR2 and ARG1. Whether hyperglycemia was the result of 
streptozotocin (STZ) treatment or a genetic mutation in the leptin receptor (type 1 and type 2 diabetes models, respectively), similar increases in TSP-4 levels, infiltration of macrophages, and increased levels of all inflammatory markers were detected, documenting higher cancer inflammation in tumors of hyperglycemic mice. In our previous work, we also found that high glucose in vitro and hyperglycemia in vivo, independently of a used model, drives the cancer growth $(5,32,33)$.

Similarly, higher macrophage infiltration of tumors and adjacent non-cancerous tissues was observed in specimens of hyperglycemic patients, parallel to the increased levels of TSP-4 in these specimens. We have previously reported that TSP-4 can be produced by endothelial, smooth muscle cells, and by macrophages $(3,5,11,13,44)$. Most of TSP4 in tumors was associated with macrophages, and only a small portion was colocalized with endothelial cells, suggesting that macrophages are the main or at least the major producers of TSP-4 in tumors.

Using BMDM isolated from WT mice, Thbs4 $4^{-/}$mice, and mice expressing a more active form of the protein P387-TSP-4 (P387-TSP4-KI), we tested the effect of high glucose on the levels of TSP-4. High glucose increased the production of TSP-4 by BMDM in WT cells.

To prove the role of TSP-4 as a mediator of proinflammatory effects of high glucose and TGF-beta, cultured BMDM from WT and Thbs4--- mice were stimulated with high glucose or with TGF-beta1. Although the deletion of TSP-4 clearly resulted in lower production of inflammatory markers by the cultured BMDM, the effects were distinct and specific, suggesting that the effects of high glucose are not mediated by TGF-beta but 
rather that the two stimuli activate non-overlapping pro-inflammatory pathways. Remarkably, the effect on the expression of Ccl2 (MCP-1) in BMDM was opposite in cells stimulated with high glucose and TGF-beta: high glucose increased it, but TGFbeta1 decreased the expression.

In vivo in EMT6 xenografts, TGF-beta1 injections increased macrophage infiltration as was detected by the staining of the tumor sections with anti-CD68 antibody. The macrophage infiltration was decreased in tumors of Thbs4/- mice, demonstrating that TSP-4 mediates the cancer inflammation.

Although both hyperglycemia and TGF-beta stimulations in vivo and in cultured BMDM resulted in increased expression and protein levels of TSP-4, the differential effects of the two stimuli on cultured BMDM and differential roles of TSP-4 in these effects of high glucose and TGF-beta1 suggested that glucose effects TSP-4 levels in TGF-betaindependent manner. The roles of TSP-4 in responses of BMDM to TGF-beta1 and high glucose were different: while both stimuli upregulated the expression of TSP-4, TSP-4 mediated the upregulation of $\mathrm{Ccl} 2$ in response to TGF-beta1 with no effect of TSP-4 KO on upregulation $/ / 6$ and Tnf. Tnf upregulation was down in TSP-4 KO cells in response to high glucose, but there was no effect of TSP-4 deletion on Cc/2 and I/6 upregulation by glucose. High glucose caused upregulation of markers of pro-inflammatory macrophages without affecting markers of tissue repair macrophages, and upregulation of all macrophage markers in response to glucose was reduced in TSP-4 KO cells. TGF-beta1 produced a more complex response, with Nos2 and Arg1 being highly 
upregulated with no effects on Cd38 and reduction in Egr2 expression, but TSP-4 KO resulted in reduction of the levels of all macrophage markers.========

Stiffening of the tumor ECM due to increased levels of collagen and fibronectin is an important event in cancer progression. Although TSP-4 mediates TGF-beta1 effects on cancer growth, angiogenesis, and inflammation, TSP-4 involvement is process-specific. When we examined the effects of TSP-4 deletion on regulation of collagen depositions in response to TGF-beta1, we found that levels of collagen IV are regulated in TSP-4independent manner: TGF-beta1 downregulated collagen IV depositions in both the WT and Thbs4 ${ }^{-/}$mice. TSP-4 deletion prevented the effect on collagen I levels.

Our work describes a role for TSP-4 in cancer inflammation and identifies the pathways, in which increased levels of TSP-4 in tumor may promote cancer growth. 
bioRxiv preprint doi: https://doi.org/10.1101/2020.01.03.894436; this version posted December 14, 2020. The copyright holder for this preprint (which was not certified by peer review) is the author/funder. All rights reserved. No reuse allowed without permission.

\section{Acknowledgments}

This work was supported by the National Institutes of Health awards R01 HL117216 and R01 CA177771 and by the American Heart Association award 17PRE33660475. 


\section{Conflict of Interests}

The authors received funding for the described work. This work was supported by the National Institutes of Health awards R01 HL117216 and R01 CA177771 to Olga

Stenina-Adognravi and by the American Heart Association award 17PRE33660475 to Jasmine Gajeton (PI) and Olga Stenina-Adognravi (sponsor).

There are no other conflicts to disclose.

\section{Ethical statement}

The work with patients' specimens was approved by the Cleveland Clinic Institutional Review Board. Animal procedures were approved by the IACUC and were in agreement with the NIH Guide for Animal Use.

\section{Data availability:}

The data that support the findings of this study are available from the corresponding author upon reasonable request. 


\section{References}

1. Yang L, Zhang Y. Tumor-associated macrophages: from basic research to clinical application. J Hematol Oncol 2017;10:58

2. Medrek C, Ponten F, Jirstrom K, Leandersson K. The presence of tumor associated macrophages in tumor stroma as a prognostic marker for breast cancer patients. BMC Cancer 2012;12:306

3. Frolova EG, Pluskota E, Krukovets I, Burke T, Drumm C, Smith JD, et al. Thrombospondin-4 regulates vascular inflammation and atherogenesis. Circ Res 2010;107:1313-25

4. Pluskota E, Stenina OI, Krukovets I, Szpak D, Topol EJ, Plow EF. Mechanism and effect of thrombospondin-4 polymorphisms on neutrophil function. Blood 2005; 106:3970-8

5. Rahman MT, Muppala S, Wu J, Krukovets I, Solovjev D, Verbovetskiy D, et al. Effects of thrombospondin-4 on pro-inflammatory phenotype differentiation and apoptosis in macrophages. Cell Death Dis 2020;11:53

6. Mosher DF, Adams JC. Adhesion-modulating/matricellular ECM protein families: a structural, functional and evolutionary appraisal. Matrix Biol 2012;31:155-61

7. Pan B, Yu H, Park J, Yu YP, Luo ZD, Hogan QH. Painful nerve injury upregulates thrombospondin-4 expression in dorsal root ganglia. J Neurosci Res 2015;93:44353 
8. Subramanian A, Schilling TF. Thrombospondin-4 controls matrix assembly during development and repair of myotendinous junctions. Elife 2014;3

9. Amy EM, Song S, Kutasovic JR, Reid LE, Valle JM, Vargas AC, et al. Thrombospondin-4 expression is activated during the stromal response to invasive breast cancer. Virchows Arch 2013;463:535-45

10. Stenina-Adognravi O, Plow EF. Thrombospondin-4 in tissue remodeling. Matrix Biol 2017

11. Frolova EG, Sopko N, Blech L, Popovic ZB, Li J, Vasanji A, et al. Thrombospondin4 regulates fibrosis and remodeling of the myocardium in response to pressure overload. FASEB J 2012;26:2363-73

12. Lu X, Wang ZC, Iglehart JD, Zhang X, Richardson AL. Predicting features of breast cancer with gene expression patterns. Breast Cancer Res Treat 2008;108:191201

13. Muppala S, Frolova E, Xiao R, Krukovets I, Yoon S, Hoppe G, et al. Proangiogenic Properties of Thrombospondin-4. Arterioscler Thromb Vasc Biol 2015; 35: 197586

14. Muppala S, Xiao R, Krukovets I, Verbovetsky D, Yendamuri R, Habib N, et al. Thrombospondin-4 mediates TGF-beta-induced angiogenesis. Oncogene 2017; $36: 5189-5198$

15. Ryu TY, Park J, Scherer PE. Hyperglycemia as a risk factor for cancer progression. Diabetes Metab J 2014;38:330-6 
16. Pisani P. Hyper-insulinaemia and cancer, meta-analyses of epidemiological studies. Arch Physiol Biochem 2008;114:63-70

17. Larsson SC, Bergkvist L, Wolk A. Glycemic load, glycemic index and breast cancer risk in a prospective cohort of Swedish women. Int J Cancer 2009;125:153-7

18. Dong JY, Qin LQ. Dietary glycemic index, glycemic load, and risk of breast cancer: meta-analysis of prospective cohort studies. Breast Cancer Res Treat 2011;126:287-94

19. Mullie P, Koechlin A, Boniol M, Autier P, Boyle P. Relation between Breast Cancer and High Glycemic Index or Glycemic Load: A Meta-analysis of Prospective Cohort Studies. Crit Rev Food Sci Nutr 2016;56:152-9

20. Melkonian SC, Daniel CR, Ye Y, Pierzynski JA, Roth JA, Wu X. Glycemic Index, Glycemic Load, and Lung Cancer Risk in Non-Hispanic Whites. Cancer Epidemiol Biomarkers Prev 2016;25:532-9

21. Nagle CM, Olsen CM, Ibiebele TI, Spurdle AB, Webb PM, Astralian National Endometrial Cancer Study G, et al. Glycemic index, glycemic load and endometrial cancer risk: results from the Australian National Endometrial Cancer study and an updated systematic review and meta-analysis. Eur J Nutr 2013;52:705-15

22. Abe H, Aida $\mathrm{Y}$, Ishiguro H, Yoshizawa K, Miyazaki T, Itagaki M, et al. Alcohol, postprandial plasma glucose, and prognosis of hepatocellular carcinoma. World J Gastroenterol 2013;19:78-85

23. Hu J, La Vecchia C, Augustin LS, Negri E, de Groh M, Morrison H, et al. Glycemic index, glycemic load and cancer risk. Ann Oncol 2013;24:245-51 
24. Dehghan $\mathrm{M}$, Mente A, Zhang X, Swaminathan S, Li W, Mohan V, et al. Associations of fats and carbohydrate intake with cardiovascular disease and mortality in 18 countries from five continents (PURE): a prospective cohort study. Lancet 2017;390:2050-62

25. Lackey DE, Olefsky JM. Regulation of metabolism by the innate immune system. Nat Rev Endocrinol 2016;12:15-28

26. Chawla A, Nguyen KD, Goh YP. Macrophage-mediated inflammation in metabolic disease. Nat Rev Immunol 2011;11:738-49

27. Oh H, Park SH, Kang MK, Kim YH, Lee EJ, Kim DY, et al. Asaronic Acid Attenuates Macrophage Activation toward M1 Phenotype through Inhibition of NF-kappaB Pathway and JAK-STAT Signaling in Glucose-Loaded Murine Macrophages. J Agric Food Chem 2019;67:10069-78

28. Pavlou S, Lindsay J, Ingram R, Xu H, Chen M. Sustained high glucose exposure sensitizes macrophage responses to cytokine stimuli but reduces their phagocytic activity. BMC Immunol 2018;19:24

29. Loeys BL, Mortier G, Dietz HC. Bone lessons from Marfan syndrome and related disorders: fibrillin, TGF-B and BMP at the balance of too long and too short. Pediatr Endocrinol Rev 2013;10 Suppl 2:417-23

30. Yokoyama H, Deckert T. Central role of TGF-beta in the pathogenesis of diabetic nephropathy and macrovascular complications: a hypothesis. Diabet Med $1996 ; 13: 313-20$ 
31. Katz LH, Li Y, Chen JS, Munoz NM, Majumdar A, Chen J, et al. Targeting TGFbeta signaling in cancer. Expert Opin Ther Targets 2013;17:743-60

32. Krukovets I, Legerski M, Sul P, Stenina-Adognravi O. Inhibition of hyperglycemiainduced angiogenesis and breast cancer tumor growth by systemic injection of microRNA-467 antagonist. FASEB J 2015; 29: 3726-36.

33. Bhattacharyya S, Sul K, Krukovets I, Nestor C, Li J, Adognravi OS. Novel tissuespecific mechanism of regulation of angiogenesis and cancer growth in response to hyperglycemia. J Am Heart Assoc 2012;1:e005967

34. El Gazaerly H, Elbardisey DM, Eltokhy HM, Teaama D. Effect of transforming growth factor Beta 1 on wound healing in induced diabetic rats. Int J Health Sci (Qassim) 2013;7:160-72

35. Grzegorzewski K, Ruscetti FW, Usui N, Damia G, Longo DL, Carlino JA, et al. Recombinant transforming growth factor beta 1 and beta 2 protect mice from acutely lethal doses of 5-fluorouracil and doxorubicin. J Exp Med 1994;180:104757

36. Amend SR, Valkenburg KC, Pienta KJ. Murine Hind Limb Long Bone Dissection and Bone Marrow Isolation. J Vis Exp 2016;110:53936

37. Raman P, Harry C, Weber M, Krukovets I, Stenina OI. A Novel Transcriptional Mechanism of Cell Type-Specific Regulation of Vascular Gene Expression by Glucose. Arterioscler Thromb Vasc Biol 2011;31:634-42 
38. Stenina OI, Krukovets I, Wang K, Zhou Z, Forudi F, Penn MS, et al. Increased expression of thrombospondin-1 in vessel wall of diabetic Zucker rat. Circulation 2003;107:3209-15

39. Raman P, Krukovets I, Marinic TE, Bornstein P, Stenina OI. Glycosylation mediates up-regulation of a potent antiangiogenic and proatherogenic protein, thrombospondin-1, by glucose in vascular smooth muscle cells. J Biol Chem 2007;282:5704-14

40. Dabir P, Marinic TE, Krukovets I, Stenina OI. Aryl hydrocarbon receptor is activated by glucose and regulates the thrombospondin-1 gene promoter in endothelial cells. Circ Res 2008;102:1558-65

41. Bhattacharyya S, Marinic TE, Krukovets I, Hoppe G, Stenina OI. Cell type-specific post-transcriptional regulation of production of the potent antiangiogenic and proatherogenic protein thrombospondin-1 by high glucose. J Biol Chem 2008;283:5699-707

42. Raman P, Harry C, Weber M, Krukovets I, Stenina OI. A novel transcriptional mechanism of cell type-specific regulation of vascular gene expression by glucose. Arterioscler Thromb Vasc Biol 2011;31:634-42

43. Stenina OI, Ustinov V, Krukovets I, Marinic T, Topol EJ, Plow EF. Polymorphisms A387P in thrombospondin-4 and N700S in thrombospondin-1 perturb calcium binding sites. FASEB J 2005;19:1893-5 
44. Stenina OI, Desai SY, Krukovets I, Kight K, Janigro D, Topol EJ, et al. Thrombospondin-4 and its variants: expression and differential effects on endothelial cells. Circulation 2003;108:1514-9

45. Frolova EG, Drazba J, Krukovets I, Kostenko V, Blech L, Harry C, et al. Control of organization and function of muscle and tendon by thrombospondin-4. Matrix Biol $2014 ; 37: 35-48$

46. Ma XJ, Wang Z, Ryan PD, Isakoff SJ, Barmettler A, Fuller A, et al. A two-gene expression ratio predicts clinical outcome in breast cancer patients treated with tamoxifen. Cancer Cell 2004;5:607-16

47. Curtis C, Shah SP, Chin SF, Turashvili G, Rueda OM, Dunning MJ, et al. The genomic and transcriptomic architecture of 2,000 breast tumours reveals novel subgroups. Nature 2012;486:346-52

48. Giovannucci E, Harlan DM, Archer MC, Bergenstal RM, Gapstur SM, Habel LA, et al. Diabetes and cancer: a consensus report. CA Cancer J Clin 2010;60:207-21

49. Suriyamurthy S, Baker D, Ten Dijke P, lyengar PV. Epigenetic Reprogramming of TGF-beta Signaling in Breast Cancer. Cancers (Basel) 2019;11:726

50. Khoshakhlagh M, Soleimani A, Binabaj MM, Avan A, Ferns GA, Khazaei M, et al. Therapeutic potential of pharmacological TGF-beta signaling pathway inhibitors in the pathogenesis of breast cancer. Biochem Pharmacol 2019;164:17-22 


\section{Figure Legends}

Figure 1. TSP-4 promotes macrophage infiltration and inflammation in vivo and in cultured bone marrow-derived macrophages (BMDM).

A: $C d 68, C d 38, E g r 2$, and Ccl2 (MCP-1) mRNA levels were measured in EMT6 mouse breast cancers grown in WT and Thbs4 ${ }^{-/}$mice. Real Time RT-PCR, $n=10$, mean \pm S.E.M. B: Expression of Thbs4, II6, Cc/2, Tnf, macrophage marker Cd68, proinflammatory macrophage markers $C d 38$ and Nos2, and tissue repair macrophage markers Egr2 and Arg1 was measured in EMT6 mouse breast cancers xenografts from WT and Thbs4/- mice.

Figure 2. Increased levels of TSP-4, inflammatory markers and infiltration of macrophages in breast cancer tumors of hyperglycemic mice. EMT6 mouse breast cancer cells were injected into mammary fat pad of hyperglycemic WT STZ-treated (A) $\mathrm{n}=10$, mean \pm S.E.M and Lepr $r^{d b / d b}$ (B) mice as described in methods, and mRNA levels of Thbs4, Ccl2, Tnf, macrophage marker Cd68, inflammatory macrophage marker Cd38, and tissue repair macrophage marker Egr2 were measured by Real Time RTPCR in tumors. $N G=$ normoglycemic, $H G=$ hyperglycemic; $n=5$, mean \pm S.E.M.; C: Immunofluorescent staining of CD68, TSP-4 and vWF, (red: Thbs4 stained with antiTSP-4, green: macrophages stained with anti-CD68 antibody, magenta: vWF stained with anti-vWF; blue: nuclei stained with DAPI). Immunostaining of EMT6 tumors harvested from normoglycemic control (upper panel) and hyperglycemic (STZ-treated, bottom panel) WT C57BL/6 mice; D: TSP-4 and macrophages were stained with corresponding antibodies as described in Methods. Immunohistochemistry images and 
quantification of protein levels in tumors from hyperglycemic (STZ) and normoglycemic (Control) mice. $\mathrm{n}=10$, Mean \pm S.E.M; scale bar $=20 \mu \mathrm{M}$.

Figure 3. TSP-4 and macrophage marker CD68 in human diabetic tissues. A: TSP4 and CD68 were stained with corresponding antibodies as described in Methods. Immunohistochemistry images and quantification of protein levels in tumors (Cancer) and adjacent non-cancerous tissue (Normal) from diabetic (Hyperglycemic) and nondiabetic (Hyperglycemic) patients. B: Immunoflurescence of tumors and adjacent noncancerous tissues from normoglycemic $(\mathrm{HbAc} 1<6)$ and hyperglycemic $(\mathrm{HbAc} 1>7)$ patients; staining of CD68, TSP-4 and vWF, (red: Thbs4 stained with anti-TSP-4, green: macrophages stained with anti-CD68 antibody, magenta: vWF stained with antivWF; blue: nuclei stained with DAPI).. Scale bar $=10 \mu \mathrm{M}$.

Figure 4. TSP-4 mediates the effects of high glucose on the levels of inflammatory markers and TSP-4 in cultured BMDM. Cultured BMDM from WT and Thbs4 ${ }^{-/}$(TSP-4 $\mathrm{KO}$ ) mice were stimulated with $25 \mathrm{mM}$ D-glucose for $24 \mathrm{~h}$. A: mRNA levels of Thbs4, Ccl2, Tnf, Il6, macrophage marker Cd68, inflammatory macrophage markers Cd38 and Nos2, and tissue repair macrophage markers Egr2 and Arg1 were measured by Real Time RT-PCR; $n=3$; mean \pm S.E.M; ${ }^{*} p<0.05$ in comparison to control of the same genotype. B, C: TSP-4 and macrophage marker CD68 were visualized in cultured BMDM using corresponding antibodies. BMDM from WT mice, Thbs $4^{-/-}$mice (TSP-4 $\mathrm{KO}, \mathrm{B})$ and mice expressing more active form of TSP-4, P387 TSP-4 (TSP-4 KI, C) were stimulated with $25 \mathrm{mM} \mathrm{L-}$ or D- glucose for $24 \mathrm{~h}$. Blue: nuclei, DAPI; green: antiCd68; red: anti-TSP-4. Scale bar $=30 \mu \mathrm{M}$. 
Figure 5. TGF-beta1 increases inflammation in mouse breast cancer. A:

Expression of Thbs4, II6, Cc/2, Tnf, a macrophage marker Cd68, a pro-inflammatory macrophage marker $C d 38$, and a tissue repair macrophage marker Egr2 was measured in EMT6 mouse breast cancers of mice injected with TGF-beta as described in Methods. $n=10$, Mean \pm S.E.M. B: CD68 was visualized in EMT6 tumors of WT and Thbs $4^{-/}$mice injected with TGF-beta1, and the stained area was quantified as described in Methods. Immunohistochemistry; $n=10$, mean \pm S.E.M; ${ }^{*} p<0.05$ as compared to corresponding no treatment control, ${ }^{\#}<<0.05$ as compared to the same treatment in different genotype.

Figure 6. A: Effects of TGF-beta1 on the levels of inflammatory markers in cultured BMDM. Cultured BMDM from WT and Thbs4 $4^{-/}$(TSP-4 KO) mice were stimulated with $10 \mathrm{ng} / \mathrm{ml}$ of TGF-beta1 for $24 \mathrm{~h}, \mathrm{n}=10$; mean \pm S.E.M; ${ }^{*} \mathrm{p}<0.05$ in comparison to control of the same genotype; B: Effect of TSP-4 KO on collagen production in breast cancer in response to TGF-beta1. TSP-4 (red), nuclei (blue), collagen I (green) and collagen IV (magenta) were visualized using corresponding antibodies. Immunofluorescence, scale bar $=50 \mu \mathrm{M}$. 
A
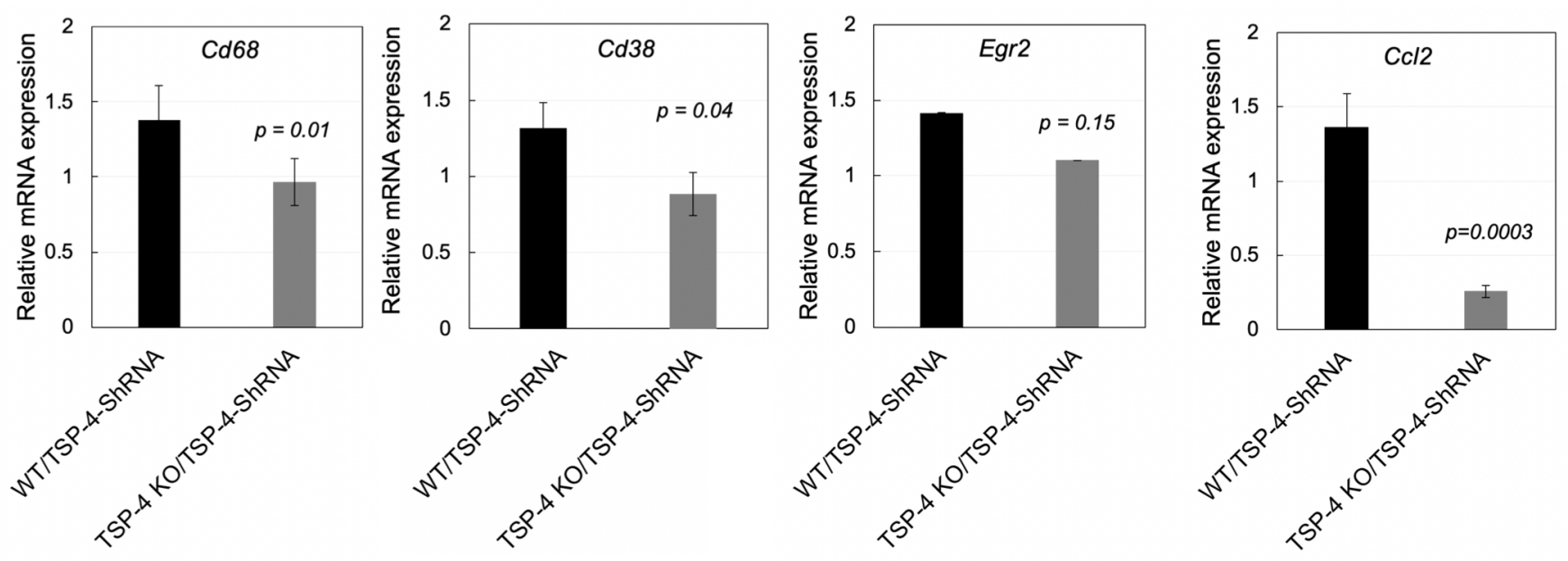

B

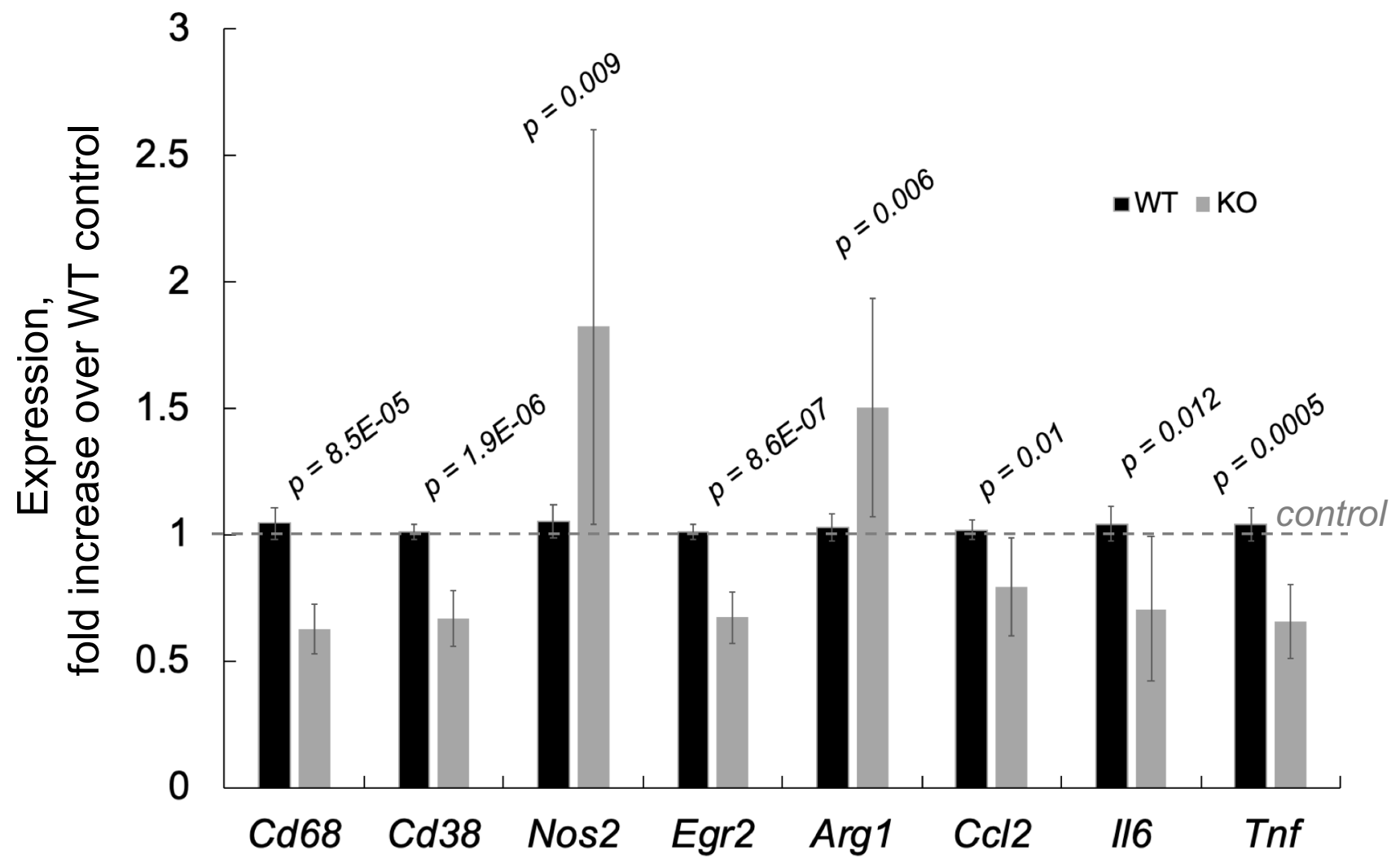


A
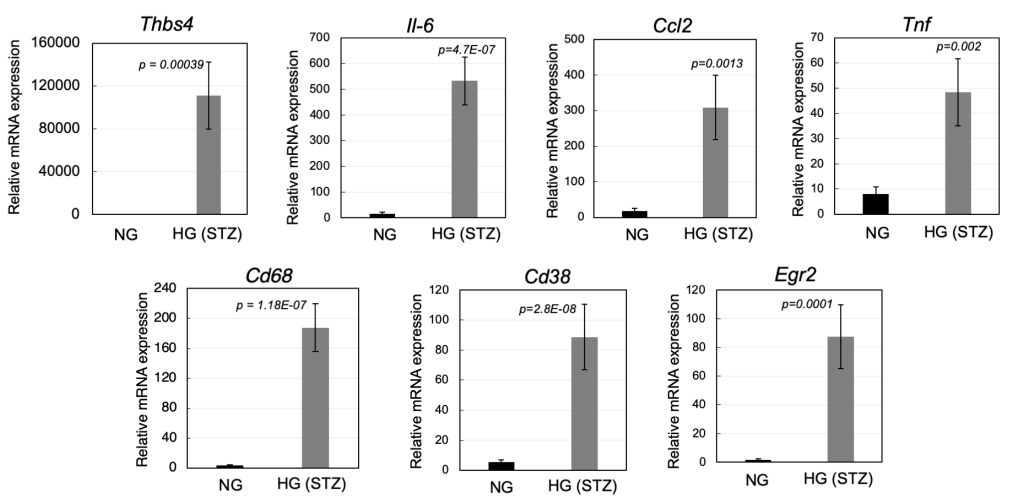

B
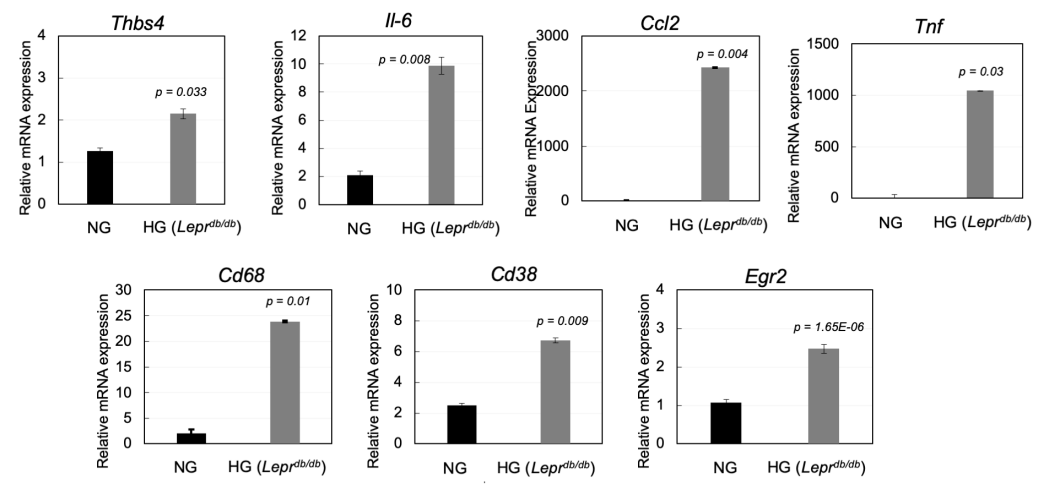

C

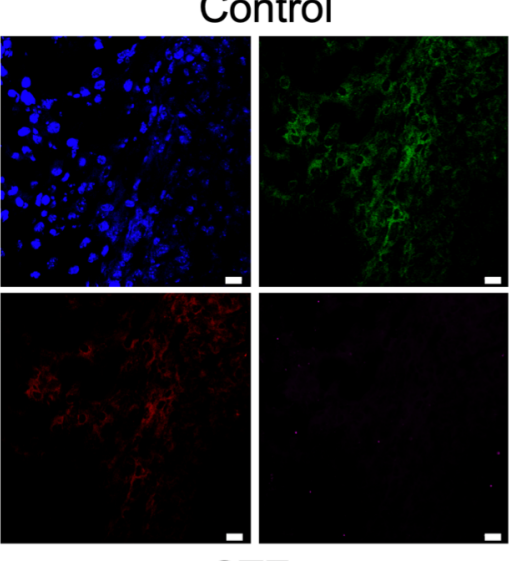

DAPI

CD68 (Alexa 488)

TSP4 (NL 557)

vWF (AF647)

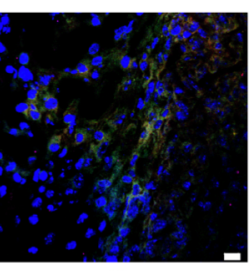

STZ
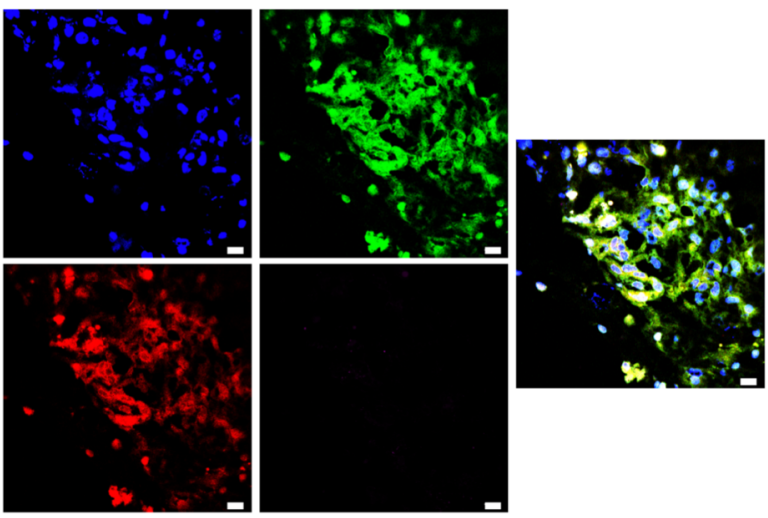

D

CD68

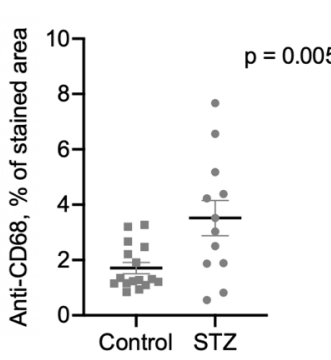

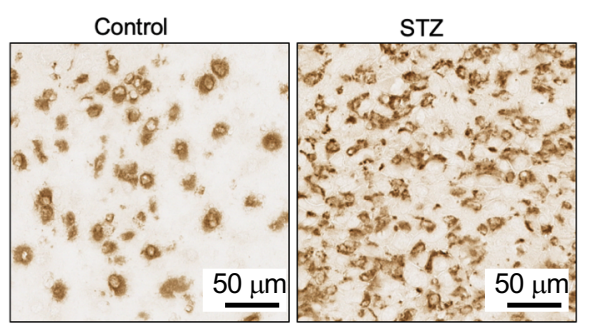

TSP-4

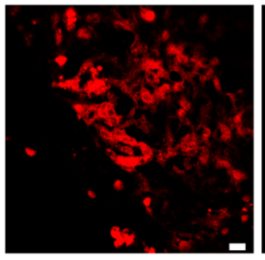

MOMA
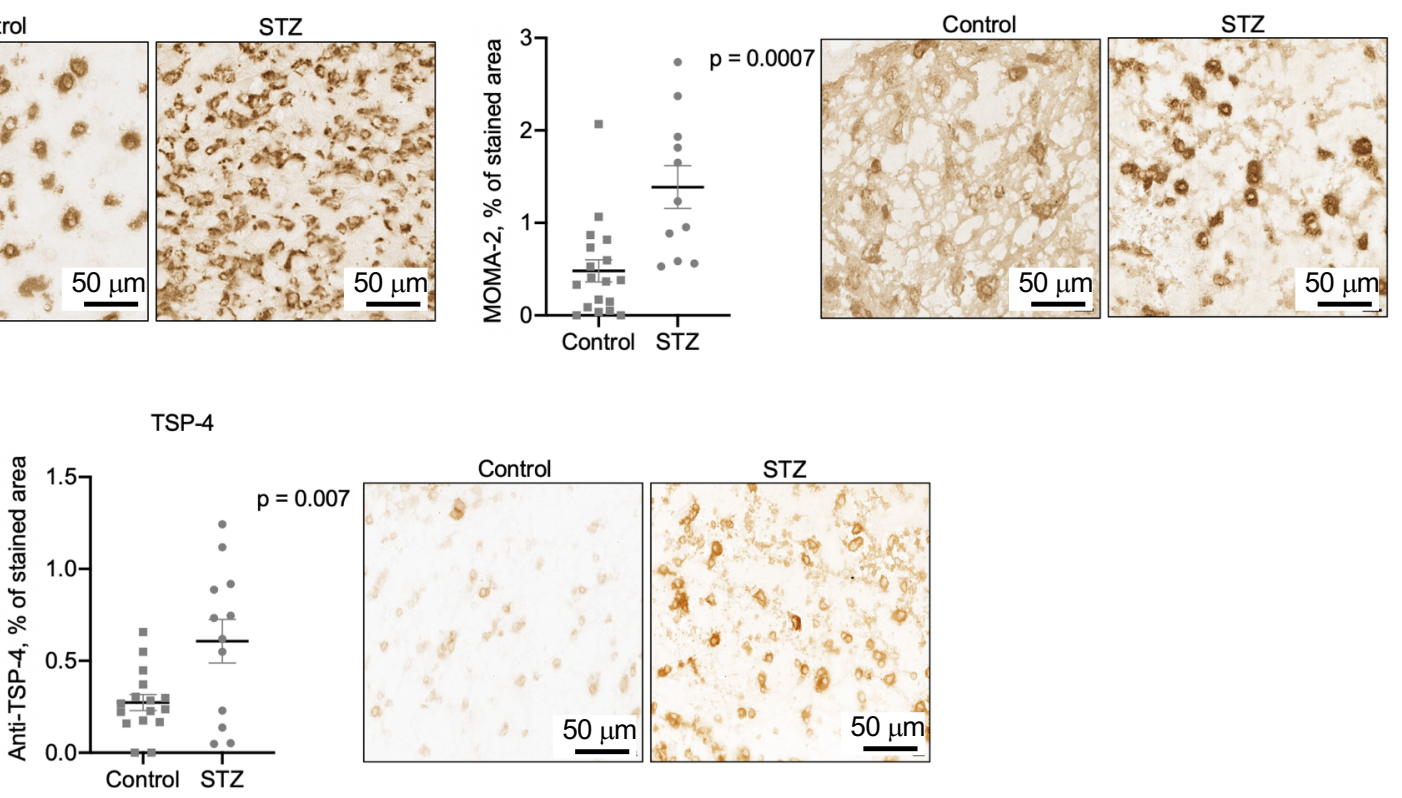

Control STZ

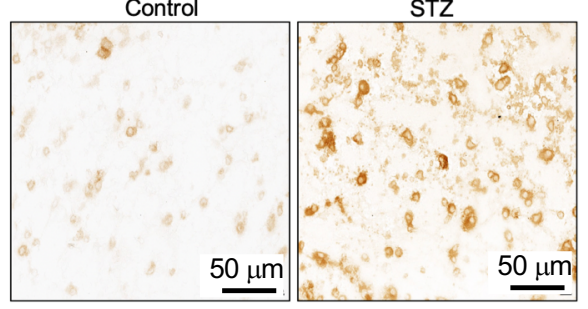



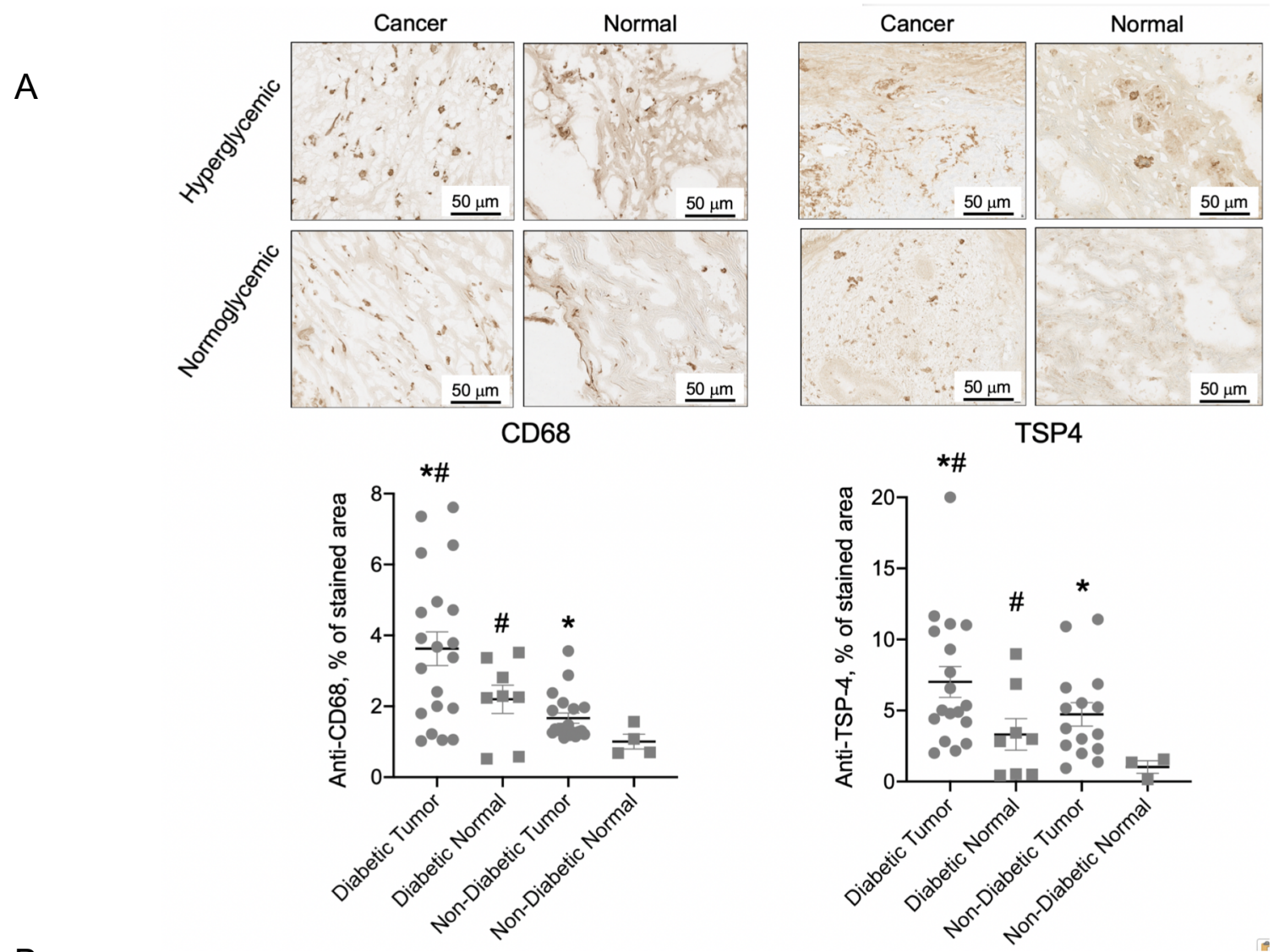

B
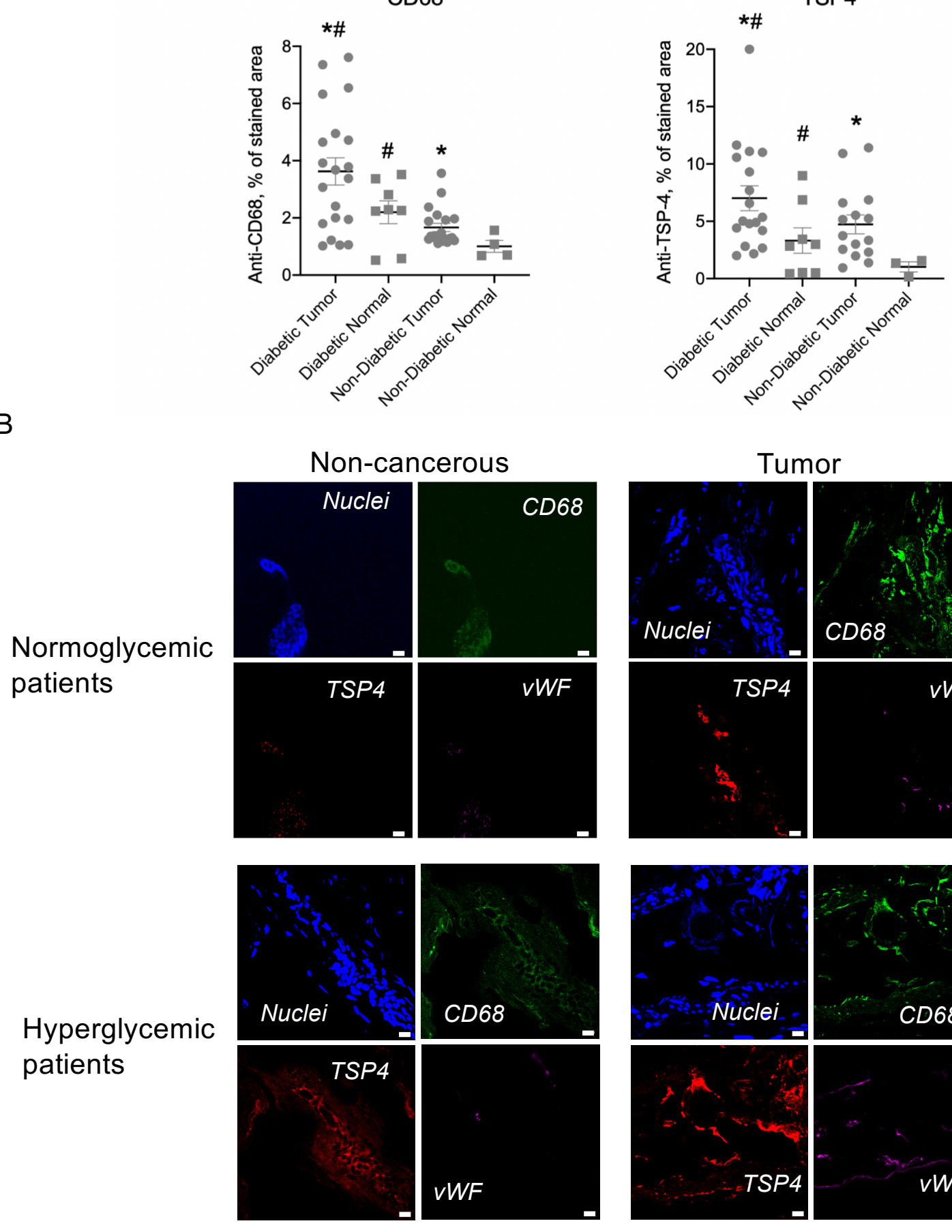

Tumor
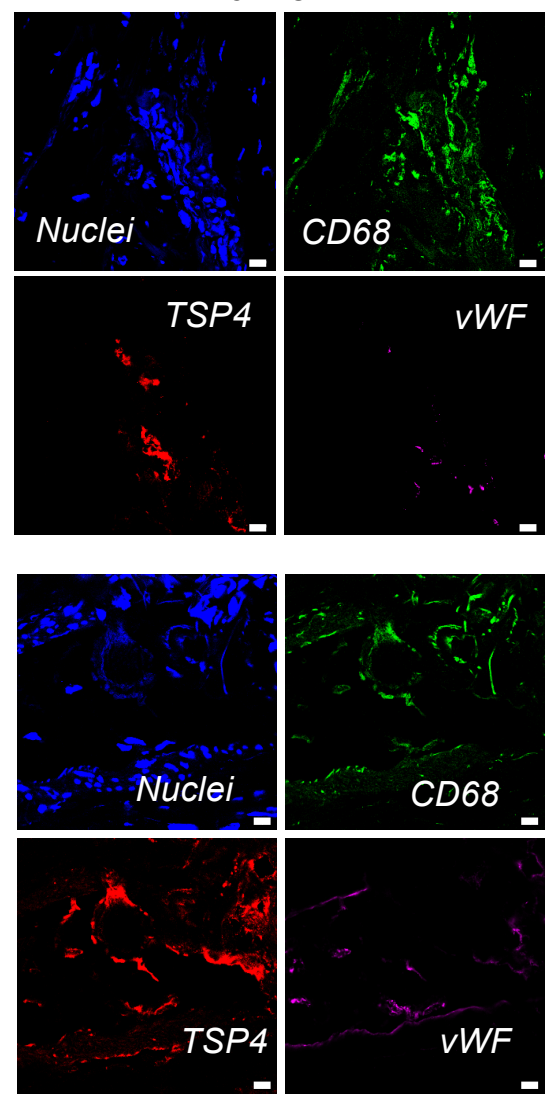
A
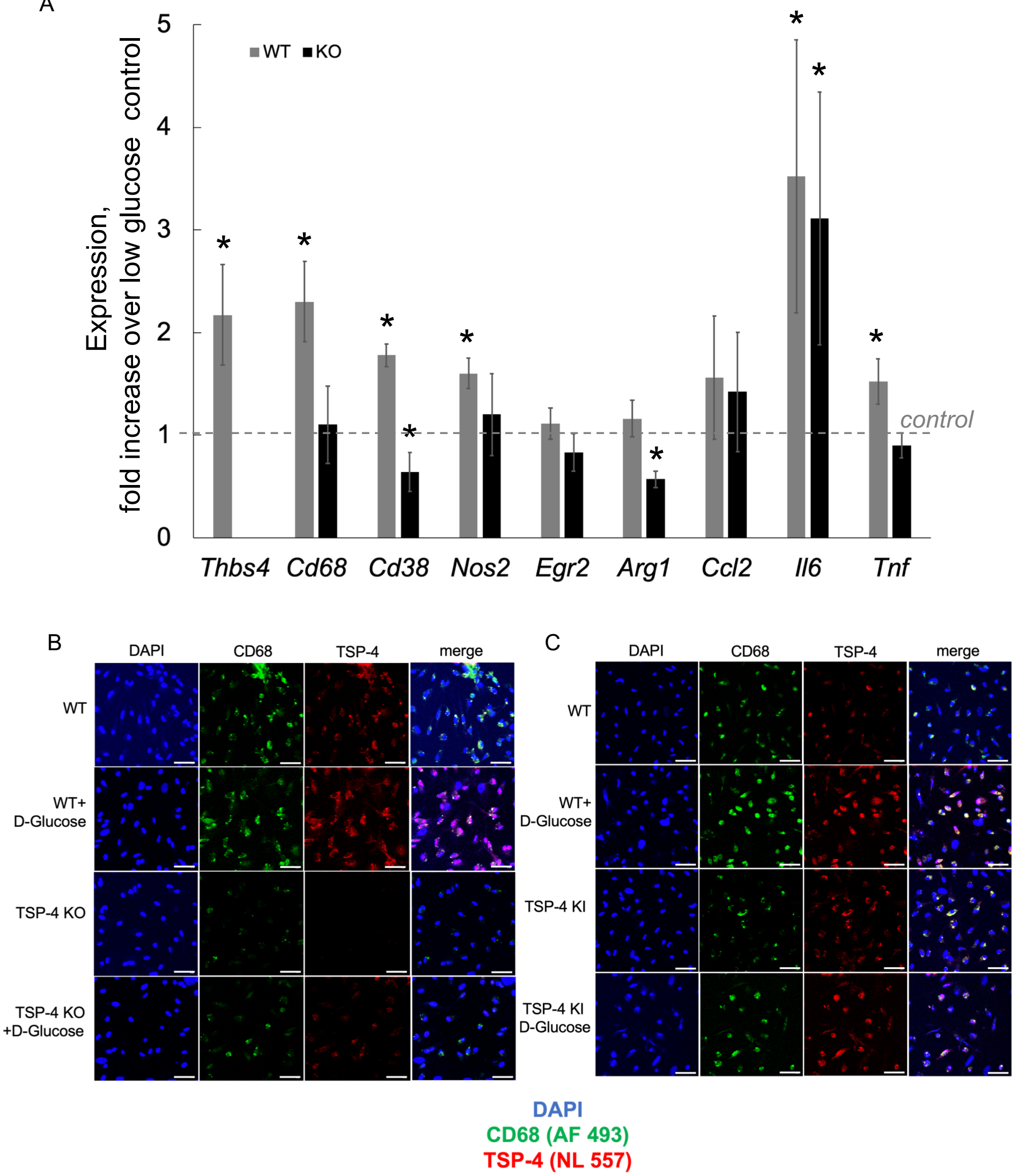
A
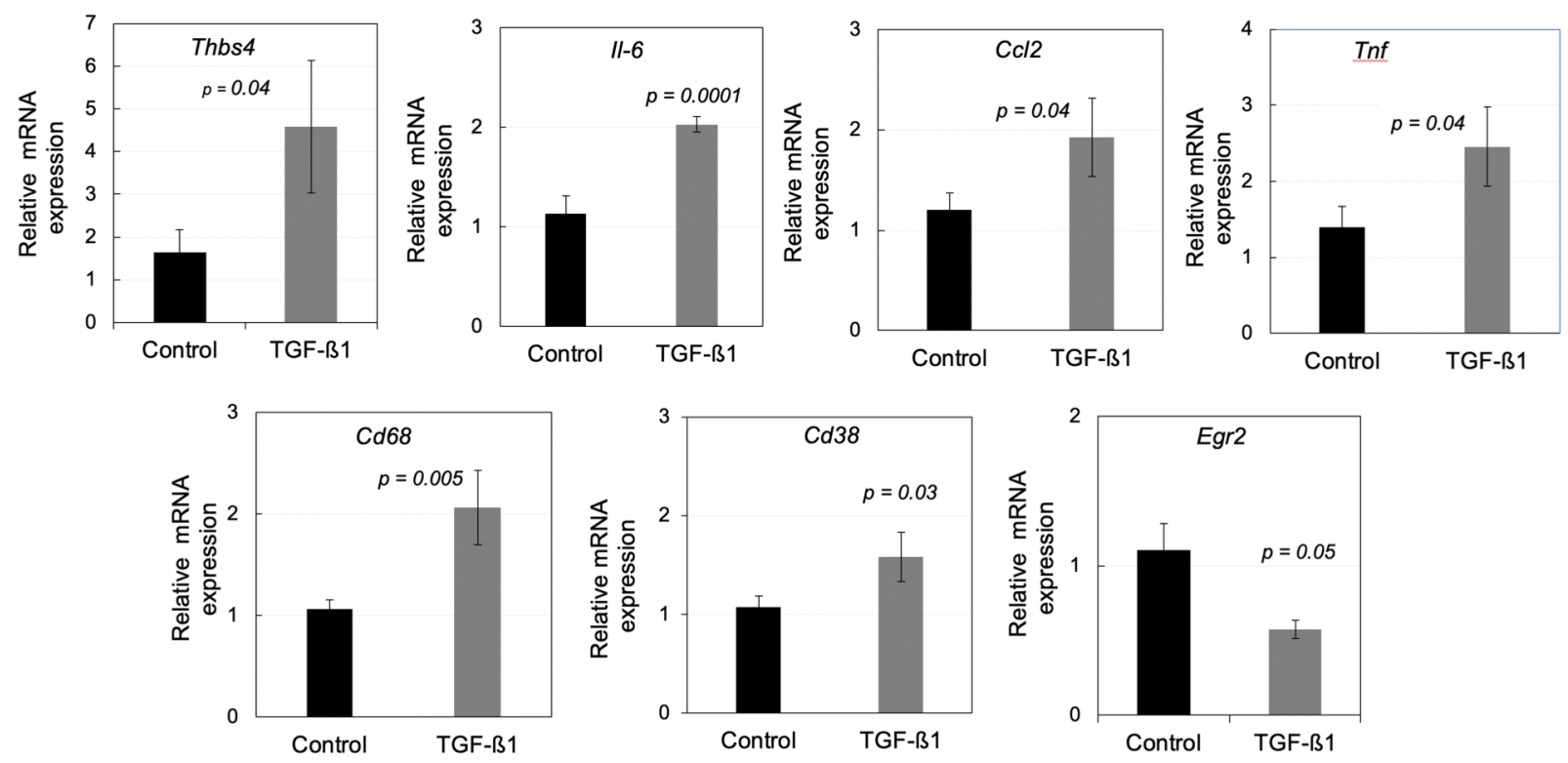

B
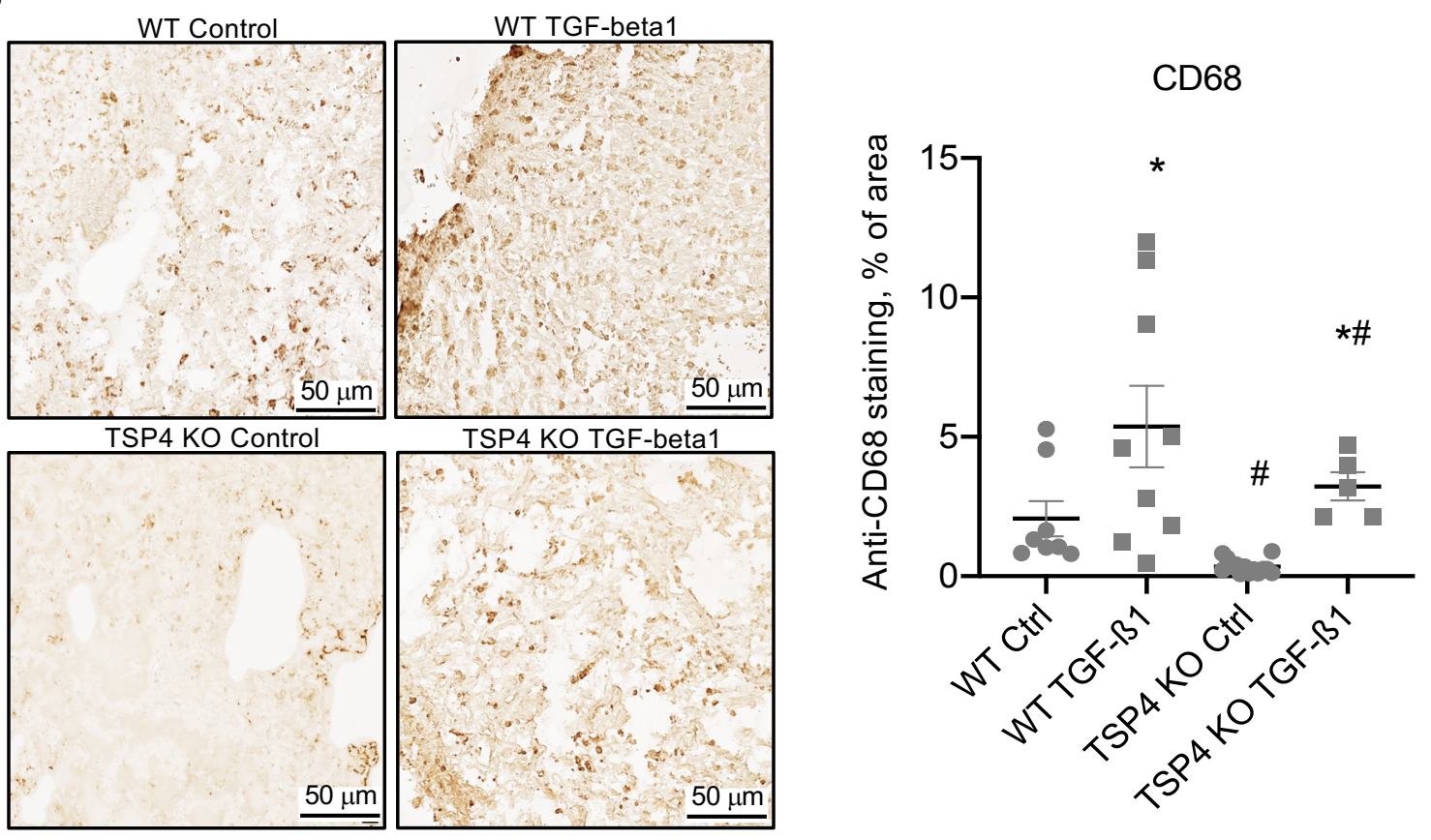


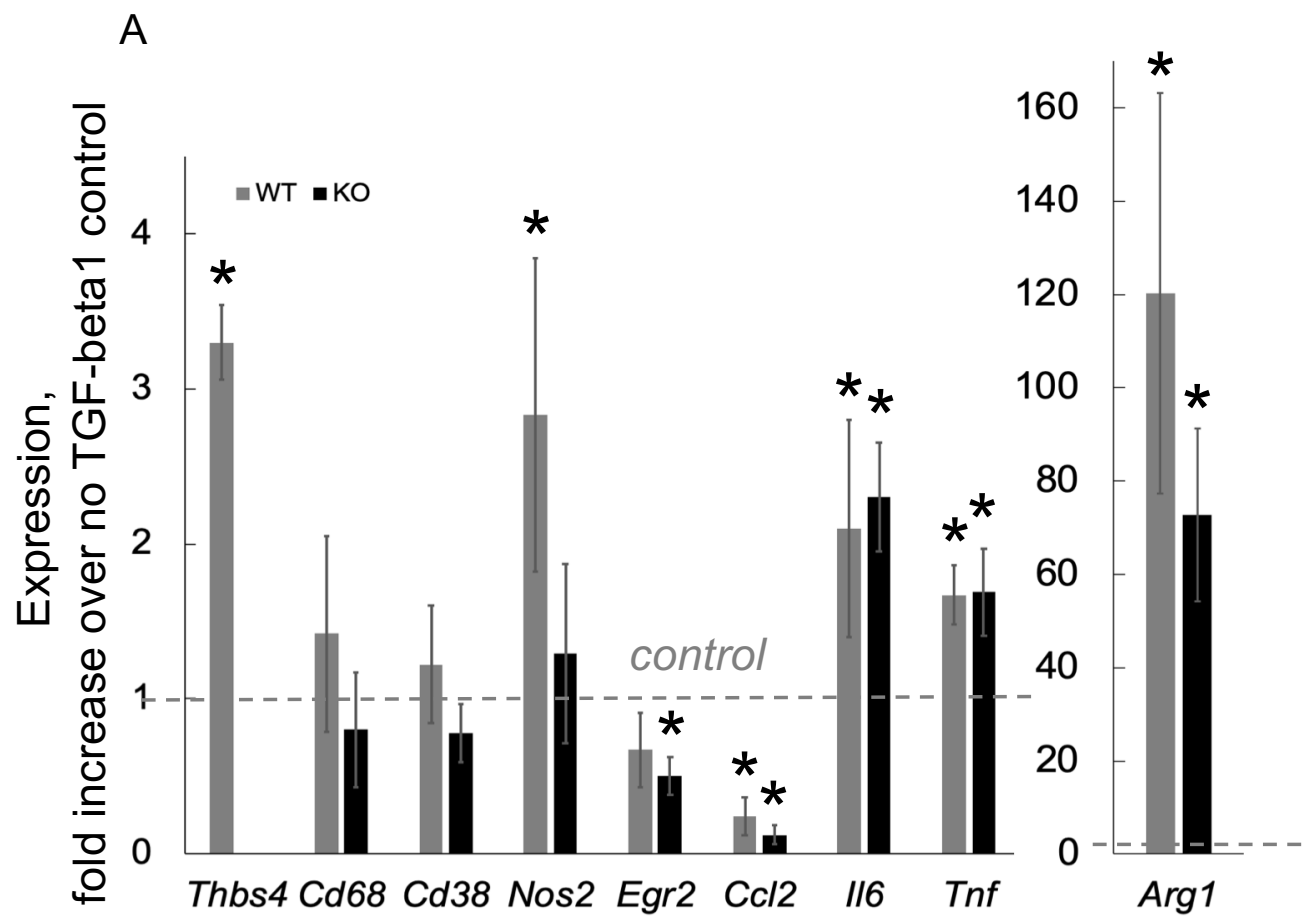

B $D A P I$

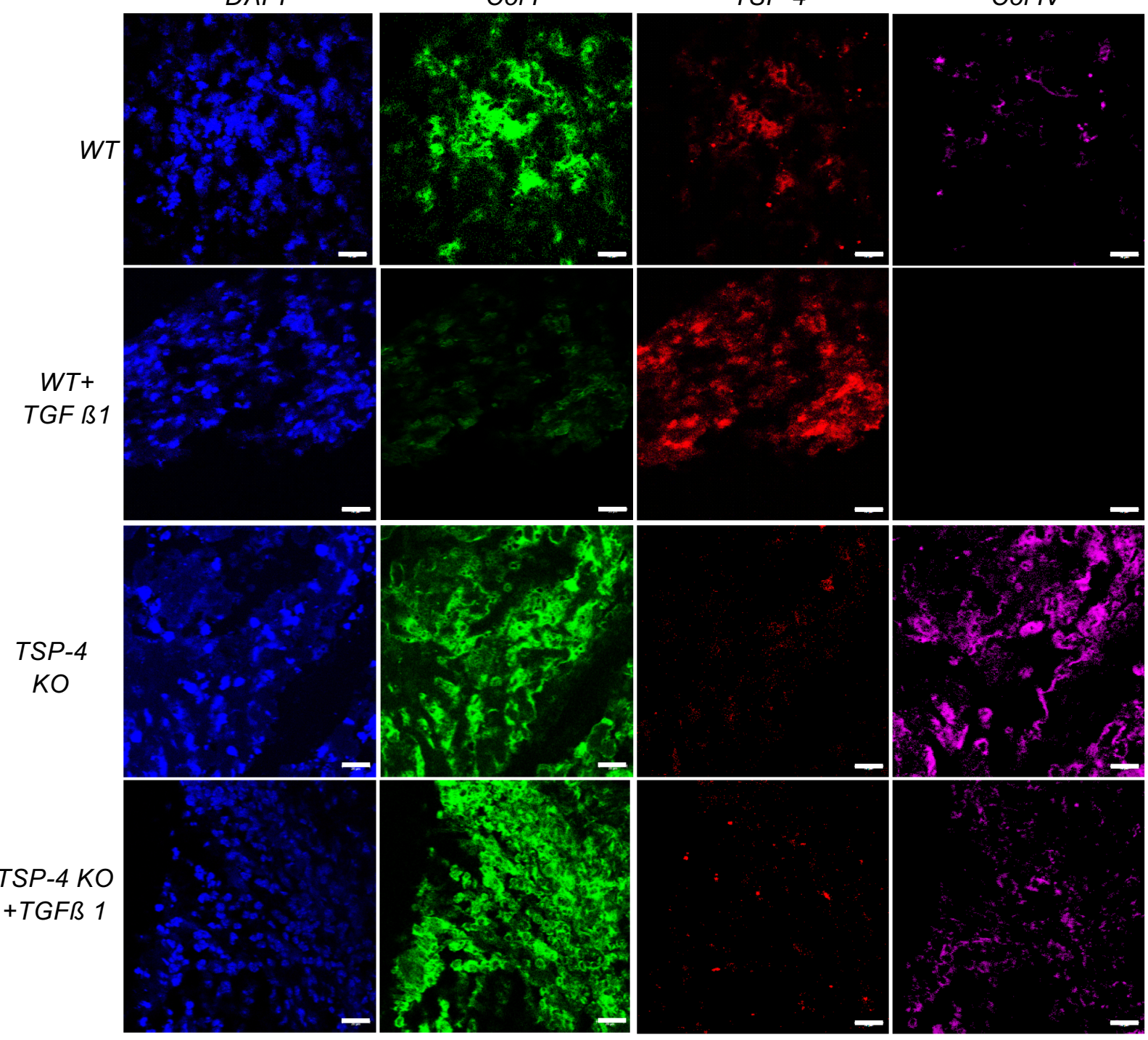


Thrombospondin-4 mediates hyperglycemia- and TGF-beta-induced inflammation in breast cancer

Santoshi Muppala, Roy Xiao, Jasmine Gajeton, Irene Krukovets, Dmitriy Verbovetskiy, and Olga Stenina-Adognravi

\section{Table of Contents:}

Suppl. Fig. 1

Suppl. Tables 1 - 6 
Normoglycemic patient
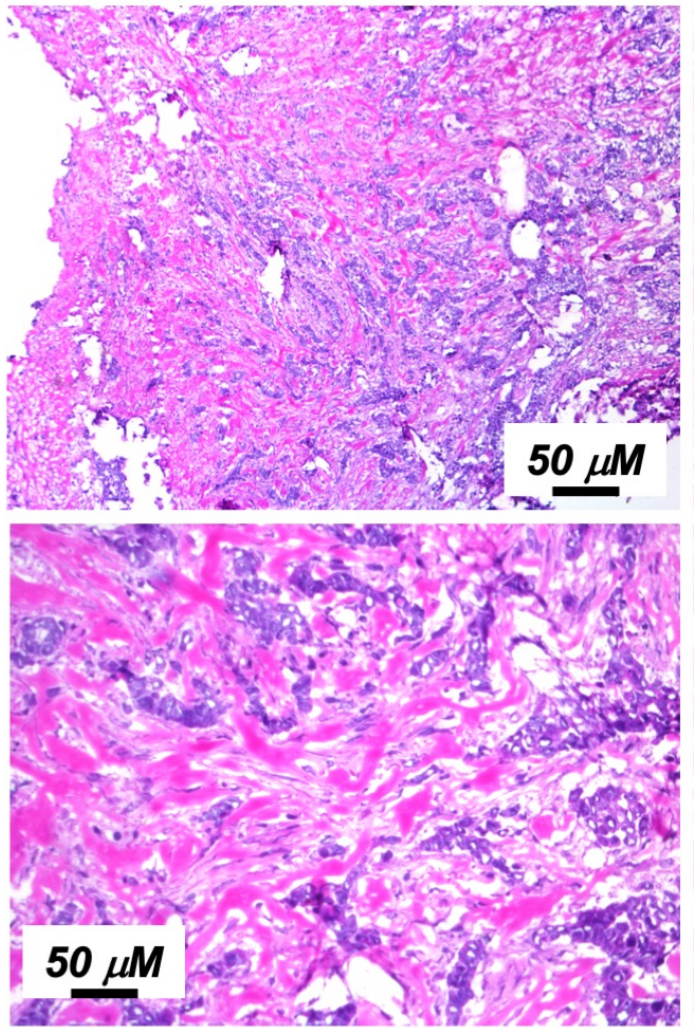

Normoglycemic mouse, EMT6

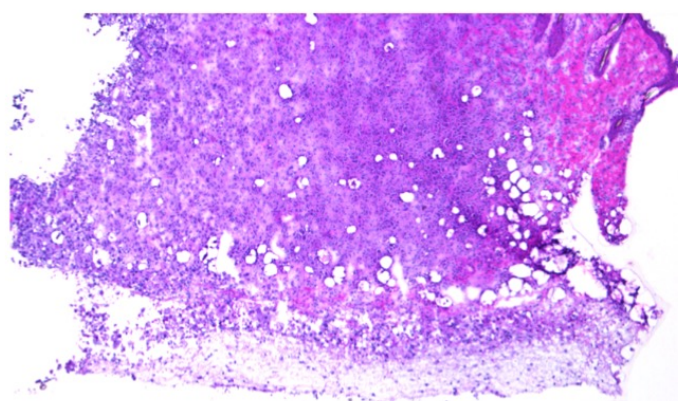

$200 \mu M$
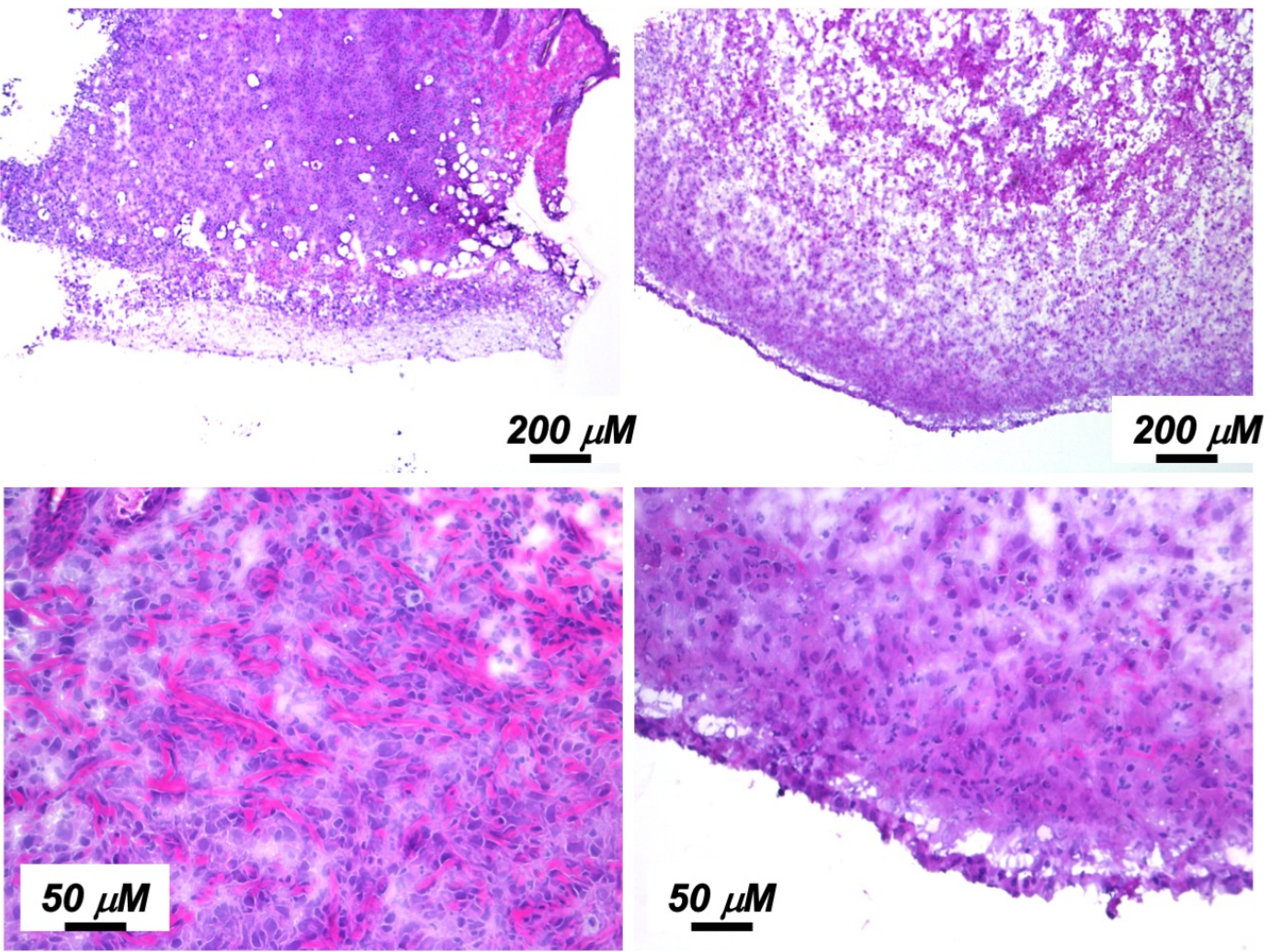

Suppl. Fig. 1. H\&E stained sections of tumors from normoglycemic and hyperglycemic patients and mice. 
Supplemental Table 1. Blood glucose levels in non-diabetic (N1 - N31) and diabetic (D1 - D43) breast cancer patients, $\mathrm{mg} / \mathrm{dl}$.

\begin{tabular}{|c|c|c|c|}
\hline Non-diabetic & Blood glucose, $\mathrm{mg} / \mathrm{dl}$ & Diabetic & Blood glucose, $\mathrm{mg} / \mathrm{dl}$ \\
\hline N1 & 53 & D1 & 68 \\
\hline N2 & 75 & D2 & 103 \\
\hline N3 & 75 & D3 & 112 \\
\hline N4 & 79 & D4 & 113 \\
\hline N5 & 79 & D5 & 116 \\
\hline N6 & 80 & D6 & 117 \\
\hline N7 & 80 & D7 & 124 \\
\hline N8 & 82 & D8 & 133 \\
\hline N9 & 84 & D9 & 136 \\
\hline N10 & 84 & D10 & 136 \\
\hline N11 & 85 & D11 & 141 \\
\hline N12 & 85 & D12 & 142 \\
\hline N13 & 85 & D13 & 144 \\
\hline N14 & 85 & D14 & 146 \\
\hline N15 & 86 & D15 & 147 \\
\hline N16 & 86 & D16 & 147 \\
\hline N17 & 87 & D17 & 147 \\
\hline N18 & 89 & D18 & 150 \\
\hline N19 & 90 & D19 & 151 \\
\hline N2O & 92 & D20 & 155 \\
\hline N21 & 93 & D21 & 159 \\
\hline N22 & 94 & D22 & 160 \\
\hline N23 & 95 & D23 & 162 \\
\hline N24 & 95 & D24 & 169 \\
\hline N25 & 95 & D25 & 170 \\
\hline N26 & 97 & D26 & 175 \\
\hline N27 & 98 & D27 & 175 \\
\hline N28 & 99 & D28 & 179 \\
\hline N29 & 101 & D29 & 181 \\
\hline N30 & 113 & D30 & 182 \\
\hline \multirow[t]{13}{*}{ N31 } & 131 & D31 & 183 \\
\hline & & D32 & 193 \\
\hline & & D33 & 199 \\
\hline & & D34 & 200 \\
\hline & & D35 & 203 \\
\hline & & D36 & 211 \\
\hline & & D37 & 214 \\
\hline & & D38 & 218 \\
\hline & & D39 & 240 \\
\hline & & D40 & 255 \\
\hline & & D41 & 278 \\
\hline & & D42 & 316 \\
\hline & & D43 & 361 \\
\hline
\end{tabular}


Supplemental Table 2. Blood glucose levels, HbA1c levels, and age of patients. Mean \pm S.E.M.; non-diabetic, $n=31$; diabetic, $n=43$.

\begin{tabular}{|c|c|c|c|}
\hline & Non-diabetic & Diabetic & $p, t$-test \\
\hline Blood glucose, $\mathrm{mg} / \mathrm{ml}$ & $88.8 \pm 2.3$ & $172.3 \pm 8.5$ & $3.40 \mathrm{E}-12$ \\
\hline HbA1c & $5.7 \pm 0.07$ & $8.7 \pm 0.3$ & $1.20 \mathrm{E}-06$ \\
\hline Age, years & $67.2 \pm 3.3$ & $20.8 \pm 4.4$ & 0.37 \\
\hline
\end{tabular}

Supplemental Table 3. Expression of TSP-4, macrophage markers, and inflammatory molecules in hyperglycemic mice (Mean \pm S.E.M.; $N=$ normoglycemic, $\mathrm{H}=$ hyperglycemic).

\begin{tabular}{|l|l|l|l|l|l|l|}
\hline \multirow{2}{*}{ Mene } & \multicolumn{3}{|c|}{ STZ-treated mice } & \multicolumn{3}{c|}{ Lepr $^{\text {db/db }}$ mice } \\
\cline { 2 - 7 } & \multicolumn{1}{|c|}{$\mathrm{N}$} & \multicolumn{1}{c|}{$\mathrm{H}$} & $\mathrm{P}, \mathrm{t}$-test & $\mathrm{N}$ & \multicolumn{1}{c|}{$\mathrm{H}$} & $\mathrm{P}$, ttest \\
\hline Thbs4 & $6.9 \pm 2.98$ & $111124.9 \pm 31134.7$ & 0.00039 & $1.26 \pm 0.16$ & $2.15 \pm 0.35$ & 0.033 \\
\hline II6 & $16 \pm 6.2$ & $532 \pm 93.2$ & $4.7 \mathrm{E}-07$ & $2.09 \pm 0.2$ & $9.89 \pm 0.6$ & 0.008 \\
\hline Ccl2 & $18.61 \pm 7.57$ & $310 \pm 90$ & 0.0013 & $4.13 \pm 1.4$ & $2429.8 \pm 862.6$ & 0.0044 \\
\hline Tnf & $8.12 \pm 2.9$ & $48.5 \pm 13.2$ & 0.002 & $2.55 \pm 0.73$ & $1046.1 \pm 544.8$ & 0.032 \\
\hline Cd68 & $3.31 \pm 1.24$ & $187.77 \pm 32$ & $1.18 \mathrm{E}-07$ & $2.06 \pm 0.52$ & $23.84 \pm 8.86$ & 0.01 \\
\hline Cd38 & $5.28 \pm 1.8$ & $88.64 \pm 21.7$ & $2.8 \mathrm{E}-08$ & $2.50 \pm 0.63$ & $6.73 \pm 0.87$ & 0.009 \\
\hline Egr2 & $1.79 \pm 0.51$ & $87.42 \pm 22.1$ & 0.0001 & $1.07 \pm 0.09$ & $2.47 \pm 0.22$ & $1.65 \mathrm{E}-06$ \\
\hline
\end{tabular}

Supplemental Table 4. Expression of TSP-4, macrophage markers, and inflammatory molecules in BMDM in response to high glucose (Mean \pm S.E.M.; $N=$ normoglycemic, $\mathrm{H}=$ hyperglycemic).

\begin{tabular}{|l|l|l|l|l|l|l|}
\hline \multirow{2}{*}{ Mene } & \multicolumn{3}{|c|}{ WT mice } & \multicolumn{3}{c|}{ Thbs4 ${ }^{-/}$mice } \\
\cline { 2 - 7 } & \multicolumn{1}{c|}{ Control } & \multicolumn{1}{c|}{ High glucose } & P, t-test & \multicolumn{1}{c|}{ Control } & High glucose & P, ttest \\
\hline Thbs4 & $1.02 \pm 0.14$ & $2.54 \pm 0.58$ & 0.03 & N/A & N/A & N/A \\
\hline II6 & $1 \pm 0.07$ & $2.68 \pm 0.4$ & 0.007 & $1.24 \pm 0.5$ & $1.51 \pm 0.42$ & 0.34 \\
\hline Cc/2 & $1.02 \pm 0.15$ & $3.42 \pm 0.47$ & 0.004 & $0.52 \pm 0.02$ & $1.6 \pm 0.33$ & 0.002 \\
\hline Tnf & $6.9 \pm 2.98$ & $111124.9 \pm 31134.7$ & 0.37 & $0.95 \pm 0.1$ & $0.68 \pm 0.16$ & 0.11 \\
\hline Cd68 & $1.05 \pm 0.23$ & $2.61 \pm 0.29$ & 0.006 & $0.55 \pm 0.07$ & $0.44 \pm 0.14$ & 0.26 \\
\hline Cd38 & $1.01 \pm 0.11$ & $1.92 \pm 0.13$ & 0.003 & $0.36 \pm 0.033$ & $0.11 \pm 0.02$ & 0.001 \\
\hline Nos2 & $1.07 \pm 0.26$ & $1.78 \pm 0.1$ & 0.03 & $0.7 \pm 0.03$ & $0.94 \pm 0.16$ & 0.096 \\
\hline Egr2 & $1.01 \pm 0.1$ & $1.8 \pm 0.3$ & 0.03 & $0.66 \pm 0.07$ & $0.42 \pm 0.065$ & 0.03 \\
\hline Arg1 & $1.03 \pm 0.3$ & $1.98 \pm 0.71$ & 0.05 & $1.3 \pm 0.43$ & $1.21 \pm .29$ & 0.44 \\
\hline
\end{tabular}


Supplemental Table 5. Expression of TSP-4, macrophage markers, and inflammatory molecules in EMT6 xenografts in response to TGF-beta1 (Mean \pm S.E.M.; Control = PBS injections; TGF-beta1 = TGF-beta1 injections).

\begin{tabular}{|l|l|l|l|}
\hline \multirow{2}{*}{ Model } & \multicolumn{3}{|c|}{ WT mice } \\
\cline { 2 - 4 } Gene & Control & \multicolumn{1}{c|}{ TGF-beta1 } & P, t-test \\
\hline Thbs4 & $1.62 \pm 0.54$ & $5.21 \pm 1.53$ & 0.04 \\
\hline II6 & $1.13 \pm 0.17$ & $2.02 \pm 0.07$ & 0.00013 \\
\hline Ccl2 & $1.21 \pm 0.16$ & $1.93 \pm 0.39$ & 0.049 \\
\hline Tnf & $1.39 \pm 0.26$ & $2.45 \pm 0.52$ & 0.040 \\
\hline Cd68 & $1.07 \pm 0.08$ & $2.06 \pm 0.36$ & 0.005 \\
\hline Cd38 & $1.08 \pm 0.10$ & $1.58 \pm 0.24$ & 0.035 \\
\hline Egr2 & $1.10 \pm 0.17$ & $0.57 \pm 0.06$ & 0.05 \\
\hline
\end{tabular}

Supplemental Table 6. Expression of TSP-4, macrophage markers, and inflammatory molecules in BMDM in response to TGF-beta1 (Mean \pm S.E.M.; Control and TGF-beta1).

\begin{tabular}{|l|l|l|l|l|l|l|}
\hline \multirow{2}{*}{ Gene } & \multicolumn{3}{|c|}{ WT mice } & \multicolumn{3}{c|}{ Thbs4 $4^{-/}$mice } \\
\cline { 2 - 7 } & Control & \multicolumn{1}{c|}{ TGF-beta1 } & P, t-test & \multicolumn{1}{c|}{ Control } & TGF-beta1 & P, ttest \\
\hline Thbs4 & $1.02 \pm 0.13$ & $3.37 \pm 0.25$ & 0.0006 & N/A & N/A & N/A \\
\hline II6 & $1.01 \pm 0.13$ & $3.35 \pm 0.8$ & 0.02 & $0.59 \pm 0.24$ & $2.74 \pm 0.65$ & 0.01 \\
\hline Cc/2 & $1.01 \pm 0.09$ & $0.24 \pm 0.05$ & 0.0009 & $1.34 \pm 0.07$ & $0.17 \pm 0.02$ & $4 \mathrm{E}-05$ \\
\hline Tnf & $1.04 \pm 0.2$ & $1.87 \pm 0.2$ & 0.02 & $0.7 \pm 0.2$ & $1.38 \pm 0.4$ & 0.09 \\
\hline Cd68 & $1.01 \pm 0.11$ & $4.22 \pm 1.01$ & 0.016 & $0.67 \pm 0.1$ & $3.45 \pm 0.82$ & 0.01 \\
\hline Cd38 & $1.00 \pm 0.07$ & $1.28 \pm 0.16$ & 0.09 & $0.94 \pm 0.07$ & $0.7 \pm 0.16$ & 0.11 \\
\hline NOS2 & $1.00 \pm 0.06$ & $3.46 \pm 0.83$ & 0.02 & $0.43 \pm 0.13$ & $1.1 \pm 0.15$ & 0.01 \\
\hline Egr2 & $1.00 \pm 0.06$ & $0.68 \pm 0.034$ & 0.003 & $0.77 \pm 0.05$ & $0.63 \pm 0.08$ & 0.009 \\
\hline Agr1 & $1.05 \pm 0.23$ & $126.6 \pm 3.48$ & $1.6 \mathrm{E}-06$ & $1.00 \pm 0.07$ & $55.63 \pm 8.9$ & 0.002 \\
\hline
\end{tabular}

